04

\title{
Влияние магнитных и электрических полей на динамику образования плазмоидов в гатчинском разряде
}

\author{
(C) Shixin Zhao, ${ }^{1}$ Chengxun Yuan, ${ }^{1}$ A.A. Кудрявцев, ${ }^{1,2}$ Jingfeng Yаo, ${ }^{1}$ Г.Д. Шабанов ${ }^{1,3}$ \\ ${ }^{1}$ Department of Physics, Harbin Institute of Technology, \\ 150001 Harbin, China \\ ${ }^{2}$ Санкт-Петербургский государственный университет, фризический факультет, \\ 199034 Санкт-Петербург, Россия \\ ${ }^{3}$ Петербургский институт ядерной физики им. Б.П. Константинова Национального исследовательского центра \\ „Курчатовский институт“, \\ 188300 Гатчина, Ленинградская обл., Россия \\ e-mail: shabanov_gd@pnpi.nrcki.ru
}

Поступило в Редакцию 23 сентября 2021 г.

В окончательной редакции 21 ноября 2021 г.

Принято к публикации 28 ноября 2021 г.

\begin{abstract}
Проанализировано поведение в магнитных и электрических полях гатчинского разряда, который используется в основном для создания аналога шаровой молнии в обычной атмосфере лаборатории. Показано, что в этих исследованиях возможно определение знака нескомпенсированного электрического заряда как в активной фазе разряда, так и в формирующихся долгоживущих светящихся образованиях. Также показано, что электрические и магнитные поля могут изменять направление движения формирующегося светящегося образования и даже полностью блокировать его образование. Рассмотрен вид и механизм существования фейерверочных шаровых молний, фотографии которых представлены в широко известных монографиях, посвященных шаровой молнии.
\end{abstract}

Ключевые слова: гатчинский разряд, долгоживущие светящиеся образования, лидер, барьерный разряд, лидерно-стримерная система, плазменный лист, плазмоид, магнитные и электрические поля, шаровая молния.

DOI: $10.21883 / J T F .2022 .03 .52132 .263-21$

\section{Введение}

В настоящей работе описываются эксперименты по исследованию гатчинского разряда в Харбинском технологическом университете (Китай). Эти исследования проводились одновременно с экспериментами, которые уже представлены в статье [1], где основное внимание было уделено изучению первой фазы разряда, когда разряд имеет гальваническую связь с источником питания.

Гатчинский разряд - это импульсный электрический разряд, осуществляемый в воздушное полупространство с электрода, имеющего отрицательную полярность и расположенного на поверхности воды. В данных экспериментах электрод противоположной полярности (анод) в виде металлического кольца находится на дне (глубина $15 \mathrm{~cm}$ ) полиэтиленовой емкости с водой диаметром $18 \mathrm{~cm}$ (рис. 1). При таком расположении электродов и диэлектрика данный разряд имеет признаки как барьерного, так и поверхностного разряда, когда два электрода разделены диэлектриком (в данном случае - водой). После подключения к этому разрядному промежутку конденсаторной батареи емкостью $0.6 \mathrm{mF}$, заряжаемой до $5.5-6.0 \mathrm{kV}$, на поверхности воды образуется плазменный лист, и с электрода, расположенного над водой, появляется струя, направленная вверх. На $\sim 80$-й ms разрядник размыкается (остаточное напряжение $\approx 3 \mathrm{kV}$ ) и струя, оторвавшись от электрода, трансформируется в светящееся образование (плазмоид ${ }^{1}$ ). В первой фазе (до $\sim 80 \mathrm{~ms}$ ) разряд гальванически связан с источником питания. Во второй фазе разряда плазмоид уже гальванически не связан с источником питания и светится за счет запасенной в первой фазе разряда энергии. И, хотя схема установки проста, но режимы работы и выбор материалов для ее элементов не очевидны и имеют много особенностей, которые подробно рассмотрены в работе [2].

При исследовании влияния электрических и магнитных полей на динамику формирования плазмоидов в гатчинском разряде были полезны данные более ранней работы [3], в которой исследовалось распределение электрических зарядов в объеме плазмоида. В [3] с помощью зонда Ленгмюра, двойного зонда и дипольной антенны были получены результаты, показывающие, что плазмоид имеет нескомпенсированный электрический заряд, который в основном расположен в тонком приповерхностном слое плазмоида (с внутренней стороны предполагаемой авторами оболочки плазмоида). Предположительно эти заряды представляют собой неидеальную плазму, в которой носители электрического заряда

\footnotetext{
${ }^{1}$ Далее в настоящей работе будет использоваться термин „плазмоид“. Мы считаем, что этот термин не отражает физической сути образующегося в разряде долгоживущего светящегося образования, но он удобнее (как более короткий) и к тому же используется основной массой исследователей.
} 

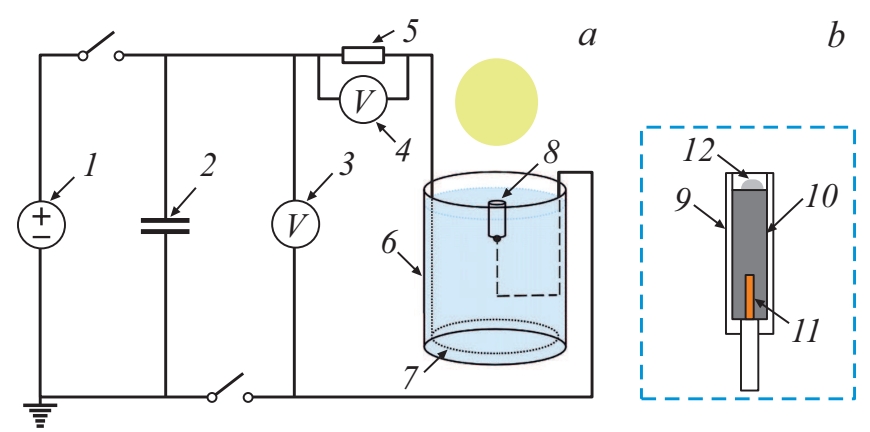

Pис. 1. $a-$ схема экспериментальной установки: $1-$ высоковольтный источник питания, 2 - конденсаторная батарея, 3, 4 - вольтметры, 5 - резистор, 6 - полиэтиленовая емкость, 7 - кольцевой электрод, 8 - центральный электрод; $b-$ конструкция центрального электрода: $9-$ кварцевая трубка, 10 - графитовый электрод, 11 - медный провод, 12 - вода или иное вещество.

имеют ближний порядок [2,3]. Это возможно, если потенциальная энергия межчастичного кулоновского взаимодействия превышает кинетическую энергию теплового движения. По мнению авторов $[2,3]$, построение такой структуры у плазмоида возможно только при соблюдении двух (основных) параллельных процессов. Первый процесс - формирование лидерно-стримерной системой однородного плазменного листа, способствующего созданию нескомпенсированного заряда у поверхности воды. Моделирование барьерных разрядов, см., например, $[4,5]$ в общих чертах соответствует экспериментальным результатам, рассмотренным в [4] и полученным в [3]. Второй параллельный процесс - создание над поверхностью воды дипольной диэлектрической оболочки, препятствующей кулоновскому разлету одноименно заряженных частиц [2]. Длительность и мощность разряда должны быть достаточными и оптимальными для выполнения этих двух процессов и не допускать, в частности, значительного расплавления (испарения) электрода. В то же время в работах [6,7] утверждается, что плазмоид практически не несет сколько-нибудь существенного нескомпенсированного заряда, что, как мы покажем далее, возможно при нарушении оригинальной методики из [2] при осуществлении гатчинского разряда.

Таким образом, из сказанного выше видно, что вопрос о наличии в плазмоидах нескомпенсированного электрического заряда остается дискуссионным и в данной работе предприняты усилия для его решения.

Основной целью настоящей работы было исследование поведения гатчинского разряда в магнитном и электрическом полях. Решались следующие задачи:

1. Показать, что поведение лидерно-стримерной системы в магнитном поле свидетельствует о наличии тока частиц с отрицательным зарядом в лидерных каналах, прорастающих над поверхностью воды и поставляющих отрицательный нескомпенсированный электрический заряд в формирующийся плазмоид.
2. Показать, что по поведению образующегося плазмоида в электрических полях можно определить знак поставленного в него нескомпенсированного электрического заряда.

Ранее автором работы [2] проводился эксперимент с использованием магнитов. Однако из-за несовершенной фоторегистрирующей техники (один кадр в одном эксперименте), был сделан лишь качественный вывод о значительном влиянии магнитного поля на разряд. Позднее в работе [8] были также проведены эксперименты по влиянию магнитного поля на гатчинский разряд. Показано, что магнитное поле может оказывать существенное влияние на начальную фазу развитие разряда.

В настоящей работе проводились эксперименты со скоростью съемки до 1000 fps с различными магнитами. Благодаря этому стала возможной визуализация как макрокартины влияния магнитного поля на разряд, так и „тонкой“ структуры особенностей поведения лидерностримерной системы в магнитном поле. В магнитном поле, например, дискообразного неодимового магнита выявились интересные особенностей поведения лидерно-стримерной системы. Наблюдаемое поведение лидерно-стримерных систем в этих экспериментах имеет существенное сходство как в опытах по пробою воздушных промежутков, так и регистрируемых в природных процессах $[9,10]$ и представляют общенаучный интерес.

\section{1. Схема установки}

Схема установки гатчинского разряда с указанием основных ее элементов приведена на рис. 1. Во введении даны „силовые“ параметры установки. Дополним это описание наиболее важными параметрами. В центре полиэтиленовой емкости находится электрод из графита, имеющий диаметр $6 \mathrm{~mm}$ и утопленный в кварцевой трубке на глубину $2-3 \mathrm{~mm}$, которая изолирует боковые поверхности электрода от воды (рис. $1, b$ ). Кварцевая трубка выступает над поверхностью воды на высоту 2-3 mm. Кольцевой электрод противоположной полярности (анод) находится в воде на глубине $15 \mathrm{~cm}$ и только на этой глубине электрод не имеет изоляционного покрытия. Графитовый электрод утапливается в кварцевую трубку из чисто технологических соображений, этим достигается строго вертикальное движение формирующегося плазмоида (дополнительно для этого в трубке создается мениск из дистиллированной воды), что важно для зондовых (и прочих) измерений [2]. Для видеосъемки разряда использовалась камера Sony FDR-AX700, которая позволяла производить видеосьемку со скоростью 500 и $1000 \mathrm{fps}$. Технология нумерации кадров видео следующая: при появлении в кадре света ему присваивается значение $0 \mathrm{~ms}$, при скорости съемки $500 \mathrm{fps}$ каждому следующему кадру добавляется $2 \mathrm{~ms}$, при скорости съемки 1000 fps каждому следующему кадру добавляется $1 \mathrm{~ms}$. Это правило относится ко всем видеоматериалам на- 
стоящей работы. Образование плазмоида очень чувствительно к параметрам отдельных элементов установки, включая механизм коммутации разряда и заземления, пример влияния на разряд элементов схемы рассмотрен, например, в [11]. Ниже мы приведем данные по влиянию одного из параметров схемы на перераспределение вкладываемой энергии между элементами разряда.

\section{2. Влияние магнитного поля на гатчинский разряд}

В первом эксперименте магнитное поле создавалось кольцеобразным ферритовым магнитом с наружным диаметром $110 \mathrm{~mm}$, с внутренним диаметром отверстия $60 \mathrm{~mm}$ и толщиной $20 \mathrm{~mm}$ (максимальное поле $88 \mathrm{mT}$ ), который подвешивался плоской стороной перпендикулярно к центральному электроду на расстоянии $20 \mathrm{~mm}$ от него и на расстоянии $10 \mathrm{~mm}$ над поверхностью воды (рис. 2). Влияние магнитного поля на разряд было снято в „белом“ свете. На рис. 2 приведены кадры из видео (эксперимента) № CO119, $500 \mathrm{fps,} \mathrm{коммутация} \mathrm{разряда}$ происходила при $5.50 \mathrm{kV}$, а при $2.58 \mathrm{kV}$ разряд прерывался. В проведенном эксперименте наблюдалось явно выраженное воздействие магнитного поля на разряд (рис. 2). При съемке в белом свете хорошо выражен подъем лидеров над поверхностью воды буквально с первых миллисекунд разряда, но в то же время стримеры на концах лидеров сохраняют связь с водой, например 16-я и 24-я ms разряда (рис. 2, c,d). Практически с 10-й ms разряда растущее ионизированное облако скрывает под собой возможно более тонкую структуру разряда.

В работе [1] формирование плазмоидов фиксировали не только в белом свете, но и в диапазоне длин волн $400-500 \mathrm{~nm}$. В настоящей работе также использовался этот прием; при съемке видео № CO118 использовали такой фильтр, $500 \mathrm{fps,} \mathrm{(рис.} \mathrm{3).} \mathrm{Коммутация} \mathrm{разряда}$ осуществлялась при напряжении на конденсаторной батарее $5.50 \mathrm{kV}$, а при $2.39 \mathrm{kV}$ разряд прерывался. Магнит был расположен в $50 \mathrm{~mm}$ от центрального электрода и его нижний срез располагался на высоте $70 \mathrm{~mm}$ над поверхностью воды. Применение фильтра в данном эксперименте позволило выявить, что движение разряда коррелирует с конфигурацией магнитного поля кольцеобразного магнита. Магнитное поле кольцеобразного магнита вблизи его поверхности несколько раз меняет свое направление (рис. 4), поэтому движение растущего вдоль поверхности магнита разряда сложное (рис. 2, 3). Чтобы упростить динамику движения разряда в магнитном поле, выбрали дискообразный магнит, у которого магнитное поле с плоской стороны магнита достаточно однородное (рис. 5).

В эксперименте № C0136 (рис. 6), $1000 \mathrm{fps,} \mathrm{исполь-}$ зовался дискообразный неодимовый магнит диаметром $50 \mathrm{~mm}$ расположенный параллельно поверхности воды и на расстоянии $50 \mathrm{~mm}$ от нее, максимальное поле магнита
$270 \mathrm{mT}$. Северный полюс магнита находился на его верхней поверхности. Коммутация разряда происходила при напряжении на конденсаторной батарее $5.50 \mathrm{kV}$, a при $2.64 \mathrm{kV}$ разряд прерывался.

В следующем эксперименте № С0138 съемка производилась также со скоростью $1000 \mathrm{fps}$ (рис. 7). Полюса магнита поменяли местами по сравнению с экспериментом на рис. 6. Коммутация разряда происходила при напряжении на конденсаторной батарее $6.50 \mathrm{kV}$, a при $2.15 \mathrm{kV}$ разряд прерывался. Магнит расположен в $50 \mathrm{~mm}$ от центрального электрода и на высоте $50 \mathrm{~mm}$ над поверхностью воды. Отметим, что эксперименты №№ C0136 и С0138 осуществлялись в прямоугольной емкости размером $\sim 28 \times 28 \mathrm{~cm}$, и длина некоторых лидеров была $20 \mathrm{~cm}$ и более. Как видно из рис. 6 и 7, движения лидеров происходят по сложным траекториям, которые напоминают таковые из работы [12]. Повышение напряжения на конденсаторной батареи на $1 \mathrm{kV}$ или изменение полярности магнита не привело к какому-то существенному изменению поведения лидеров в открытой атмосфере воздуха.

Предполагается, что плазмоид, образовавшийся в стандартных условиях [2], имеет оболочку, однако существование оболочки не имеет строгого доказательства. В работе [2] приводятся рис. 3 и 4, на которых показано, что если с образовавшегося плазмоида снимается часть электрического заряда, то оболочка изменяет свой вид, она становится более рыхлой. В комментарии к рис. 7 из [2] объясняется, что оболочка визуализирована. Ранее в [3] было показано, что оболочка на этом снимке (рис. 7 из [2]) обособлена от внутреннего светящегося наполнения и имеет не только графическое, но и инструментальное сопровождение, подтверждающее это построение в виде графика распределения электрического заряда по объему плазмоида. К сожалению, нет химического состава, толщины, удельного веса оболочки, что оставляет вопрос наличия оболочки, строго говоря, открытым. Далее по тексту предполагаем, что оболочка существует.

Как было показано в [1], оболочка лучше наблюдается в диапазоне длин волн 400-500 nm. Приведем кадры из видео №№ C0139 и С0140, $1000 \mathrm{fps,} \mathrm{снятые} \mathrm{в} \mathrm{этом}$ диапазоне длин волн (рис. 8). В эксперименте № C0139 коммутация разряда происходила при напряжении на конденсаторной батарее $6.50 \mathrm{kV}$, а при $2.19 \mathrm{kV}$ разряд прерывался. Магнит расположен в $50 \mathrm{~mm}$ от центрального электрода и на высоте $50 \mathrm{~mm}$ над поверхностью воды и электрода. Область разряда под магнитом в этом диапазоне длин волн смотрится как сфера диаметром 50-60 mm с исходящими из нее лидерами (рис. 8, $a, b$ ). Далее приведем эксперимент № $\mathrm{C} 0140$ (рис. 8, $, d, e, f$ ), где начальное/конечное напряжение конденсаторной батареи при коммутации разряда $6.50-2.17 \mathrm{kV}$ и оно практически такое же, как и в предыдущем эксперименте. Но магнит диаметром $50 \mathrm{~mm}$ расположили над электродом на $10 \mathrm{~mm}$ ниже, чем в эксперименте № С0139. В связи с этим разряд стал развиваться в более сильном магнитном поле. Однако, как видно на 

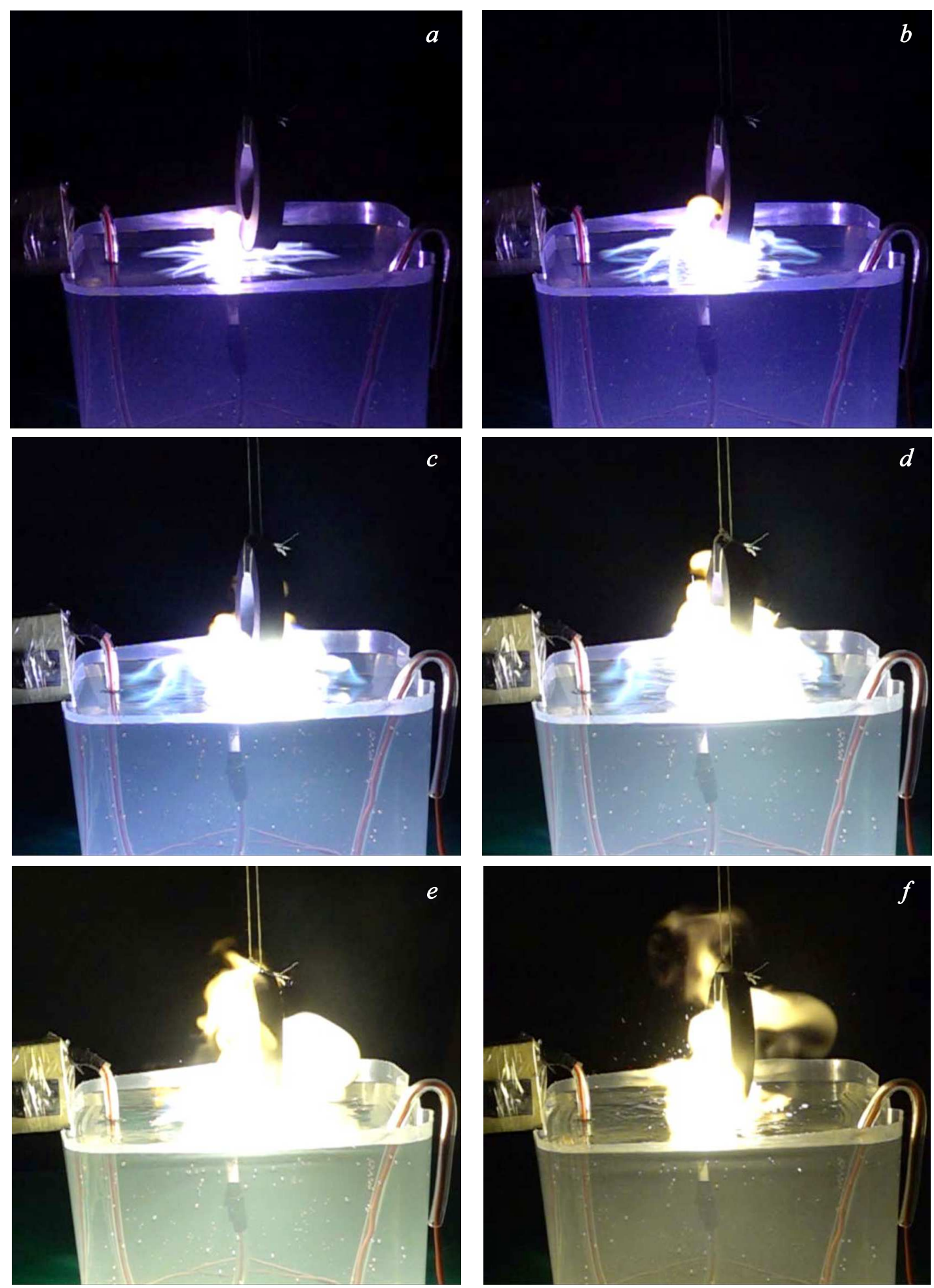

Рис. 2. Динамика развития разряда в магнитном поле кольцеобразного магнита, где кадры видеосъемки соответствуют: 2 (a), $6(b), 16(c), 24(d), 50(e)$ и $90 \mathrm{~ms}(f)$ разряда (эксперимент № CO119).

рис. 8, варьирование высоты расположения магнита над электродом $( \pm 10 \mathrm{~mm})$ и начального напряжения конденсаторной батареи $( \pm 1 \mathrm{kV})$ не привело к существенному изменению вида разряда. Сравним рисунки из [1] рис. 4 с рис. 8 настоящей работы. В разряде без магнитного поля [1] рис. 4 формирование оболочки происходит до конца первой фазы разряда (в первом приближении). На рис. 8 формирование оболочки происходит в магнитном поле в первые несколько ms, но в дальнейшем оболочка разрушается и все превращается в ионизированное обла- 

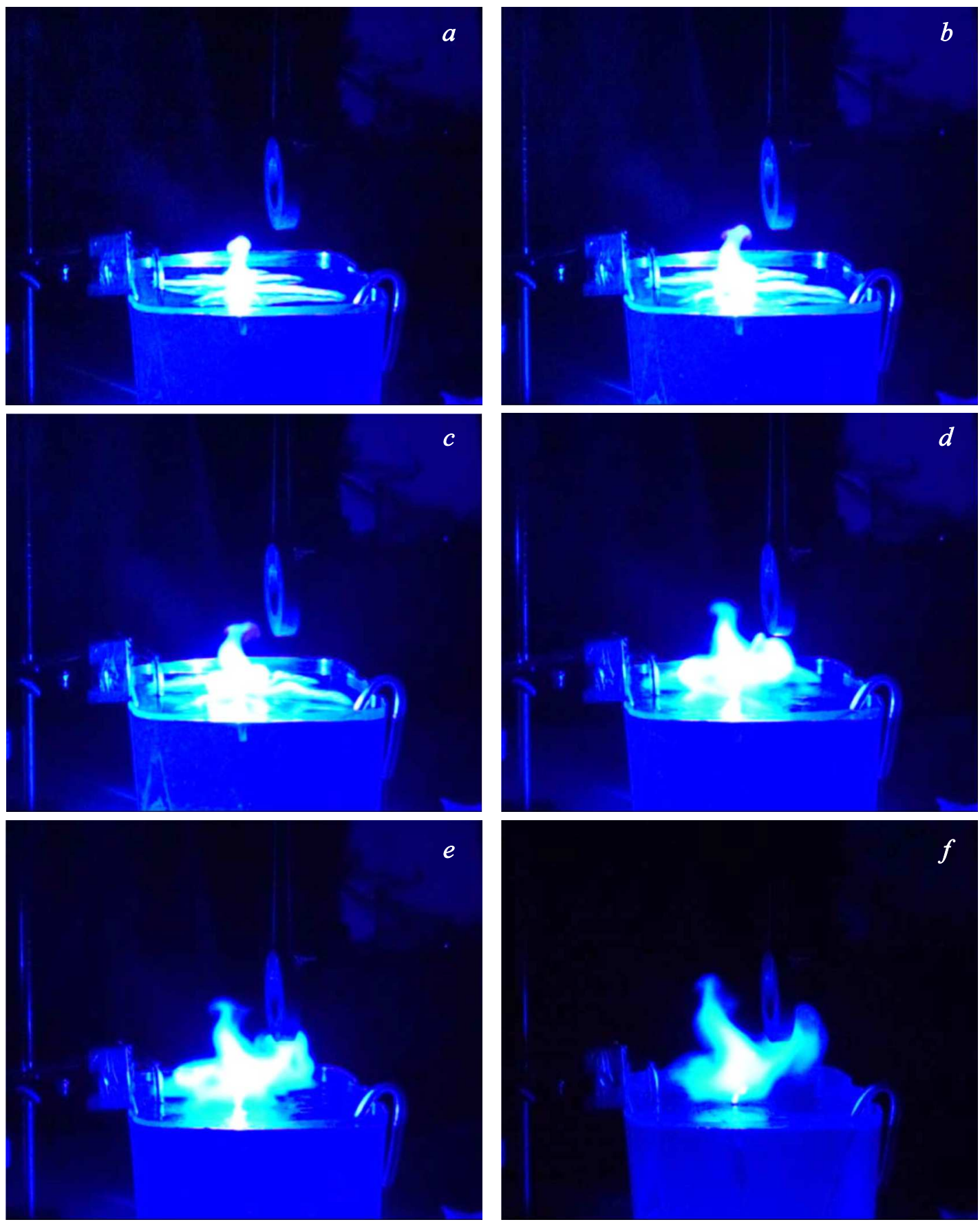

Рис. 3. Развитие разряда в магнитном поле (съемка в диапазоне длин волн $400-500 \mathrm{~nm})$, где кадры видеосъемки соответствуют: $6(a), 12(b), 20(c), 44(d), 62(e), 100 \mathrm{~ms}(f)$ разряда (эксперимент № CO118).

ко. Ниже мы приведем кадры ионизированного облака из более выразительных для этого эффекта экспериментов (рис. 9, 10).

Следующая серия экспериментов (рис. 9, 10) оказалась интересной и дает возможность определения знака зарядов как в ионизированном облаке, так и текущих в растущих лидерах. В эксперименте № C0131 (рис. 9) начальное/конечное напряжение конденсаторной батареи при коммутации разряда составляло $5.50-2.44 \mathrm{kV}$.
Магнит находится над водой на расстоянии $25 \mathrm{~mm}$, северный полюс магнита $(\mathrm{N})$ находится на нижней поверхности кольцеобразного магнита, скорость съемки 1000 fps. В эксперименте № C0134 (рис. 10) полюса магнита поменяли местами, начальное/конечное напряжение конденсаторной батареи составило $6.5-2.48 \mathrm{kV}$. Магнит находится над водой на расстоянии $30 \mathrm{~mm}$, и теперь уже южный полюс магнита $(\mathrm{S})$ находится на нижней поверхности, скорость съемки 1000 fps. 


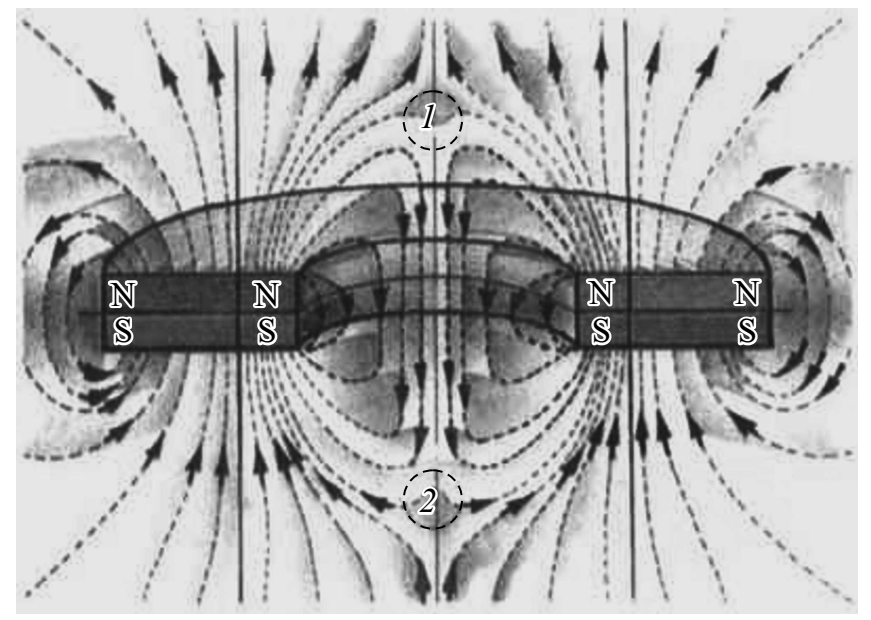

Pис. 4. Силовые линии магнитного поля кольцеобразного магнита.

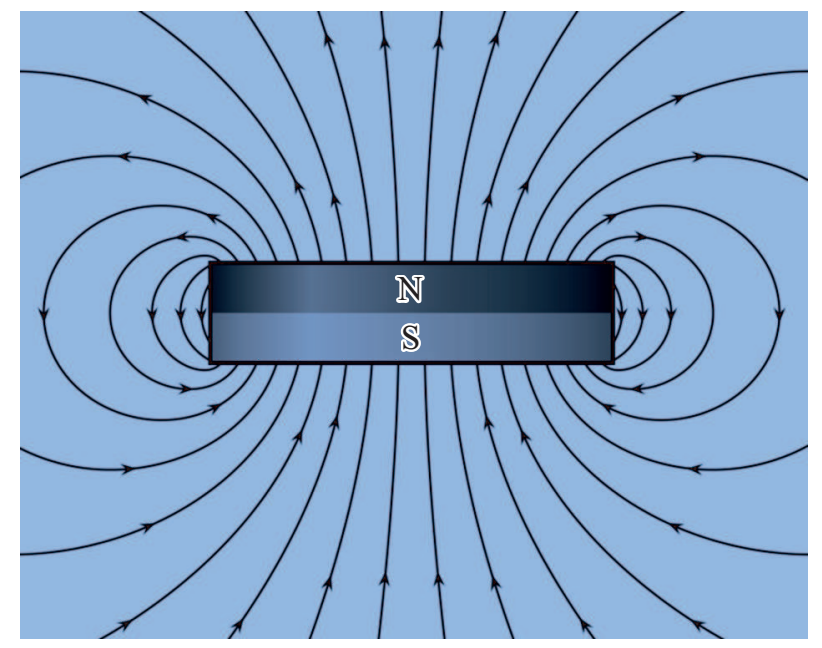

Рис. 5. Силовые линии магнитного поля дискообразного магнита.

На рис. 9, $f$ и $10, e, f$ наблюдается ионизированное облако, которое препятствует построению оболочки и соответственно образованию плазмоида. При просмотре и анализе видео со скоростью 1-2 кадров в секунду (снятых со скоростью $1000 \mathrm{fps}$ ) складывалось впечатление, что вид лидерно-стримерной системы постепенно сменяется на ярко светящееся белое облако, окутывающее магнит. Однако при скорости прокрутки видео 5-10 кадров в секунду наблюдается более сложная картина. Во-первых, облако равномерно вращается, во-вторых, наблюдаются сильные турбулентные потоки, из-за которых облако постоянно меняет свою конфигурацию. Естественно предположить, что вращение облака связано с силой Лоренца, которая действует на движущиеся заряженные частицы, и эта сила максимальна, если движение осуществляется перпендикулярно направлению магнитного поля. Начальная стадия первой фазы гатчинского разряда представляет собой движение лидеров по поверхности воды, которые в экспериментах (рис. 9, 10) осуществляются в магнитном поле как перпендикулярном поверхности воды, так и движению лидеров. В эксперименте, снятом на видео № C0131 (рис. 9), южный полюс магнита расположен сверху, вращение облака происходит по часовой стрелке. Это говорит о том, что движения облака инициируются отрицательными зарядами. Тогда при смене полярности магнита № C0134 (рис. 10) (северный полюс на верхней поверхности магнита) движение облака должно измениться на противоположное, против часовой стрелки, что и наблюдалось в эксперименте.

Для лучшей иллюстрации вышеприведенного были оптимизированы параметры разряда, геометрия эксперимента и ракурс съемки. Для визуализации силы Лоренца необходимо было создать равномерность и оптимальную интенсивность магнитного поля в зоне прорастающих лидеров. Дополнительно к найденной конфигурации эксперимента для уменьшения деструктирующей роли электрического поля в схему были внесены изменения, добавлены активное и индуктивное сопротивления. Для решения данной задачи был выбран приведенный ниже вариант.

На рис. 11 показано магнитное поле использованного в экспериментах №№ C0177 и С0178 магнита. Из рис. $11, b$ видно, что магнитное поле на поверхности воды под магнитом достаточно равномерное $(5-6 \mathrm{mT})$, но на периферии емкости диаметром $18 \mathrm{~cm}$ поле становится менее $0.1 \mathrm{mT}$. Благодаря внесенным изменениям удалось с лучшим разрешением и более четкой геометрической картиной проиллюстрировать силу Лоренца.

Вращение движущихся заряженных частиц вместе с их носителем - лидером - зафиксировали в перпендикулярном магнитном поле в следующих двух экспериментах, которые приведены на рис. 12 и 13. Кольцевой магнит расположен непосредственно над центральным электродом, а его нижняя поверхность на $5 \mathrm{~cm}$ выше центрального электрода. Внутренний диаметр кольцевого магнита составляет $46 \mathrm{~mm}$, наружный - $101 \mathrm{~mm}$, высота - $18 \mathrm{~mm}$. Максимальная напряженность магнитного поля - $115 \mathrm{mT}$.

В эксперименте № C0177 начальное/конечное напряжение конденсаторной батареи при коммутации разряда составляло $6.5-3.25 \mathrm{kV}$, видео - $1000 \mathrm{fps}$. На верхней поверхности магнита северный полюс $(\mathrm{N})$. Получено вращение лидеров против часовой стрелки (рис. 12).

В эксперименте № C0178, начальное/конечное напряжение конденсаторной батареи составляло $5.5-3.10 \mathrm{kV}$, видео - $1000 \mathrm{fps}$. На нижней поверхности магнита северный полюс $(\mathrm{N})$.

Таким образом, приведенные эксперименты показали, что магнитное поле влияет на динамику движения как лидерно-стримерной системы, так и на образующееся в разряде ионизированное облако.

Далее, на следующем этапе, были выполнены эксперименты по влиянию электрического поля. 

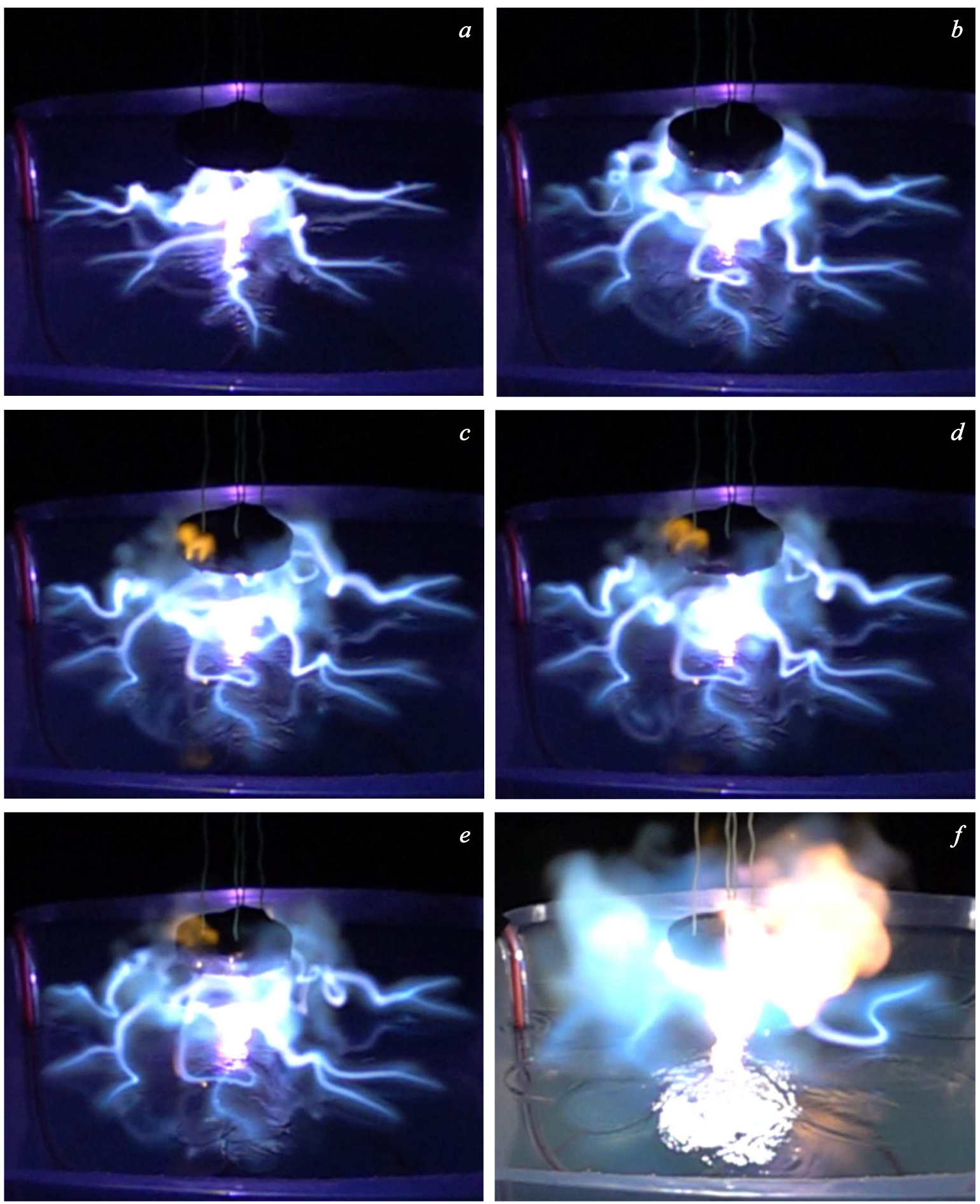

Рис. 6. Динамика развития разряда в магнитном поле дискообразного магнита, где кадры видеосъемки соответствуют: $5(a)$, $10(b), 11(c), 12(d), 13(e)$ и $40 \mathrm{~ms}(f)$ разряда (эксперимент № C0136).

3. Влияние электрического поля на гатчинский разряд, определение знака нескомпенсированного электрического заряда плазмоида

Ранее ряд исследователей, например $[3,7,8]$, сталкивались с такими сложностями использования зондовых методов, как расплавление термопар в [7] или взрыв зондов в [8]. В связи с этим в настоящей наботе предложен альтернативный метод определения заряда плазмоидов.

Для этого нержавеющую полосу размером $100 \times 270 \mathrm{~mm}$ толщиной $0.1 \mathrm{~mm}$ повесили в $75 \mathrm{~mm}$ от электрода и $75 \mathrm{~mm}$ над водой, на которую подали 

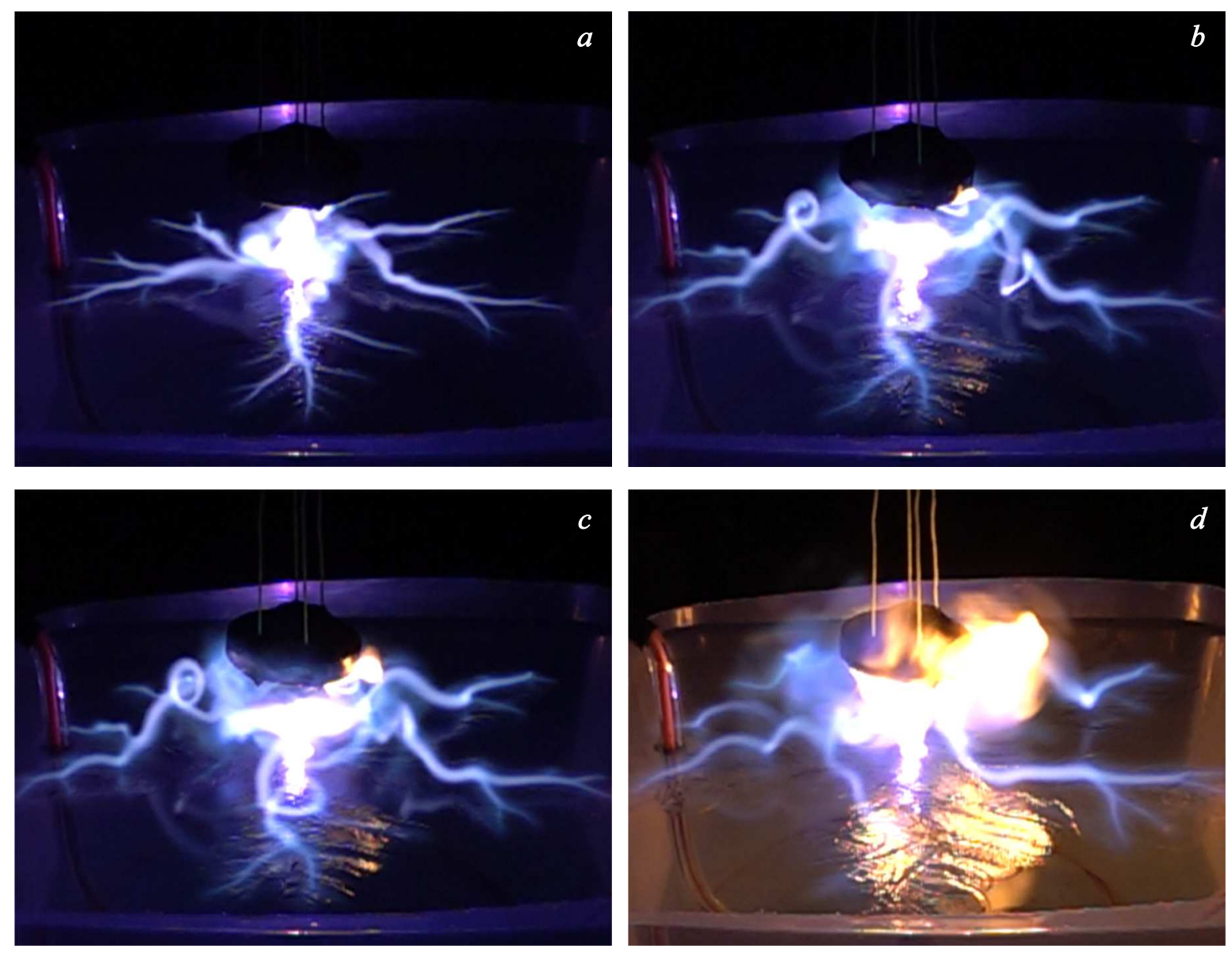

Рис. 7. Динамика развития разряда в магнитном поле с инверсной его направленностью по отношению к эксперименту, приведенному на рис. 6; кадры видеосъемки соответствуют: $3(a), 7(b), 8(c)$ и $16 \mathrm{~ms}(d)$ разряда (эксперимент № С0138).

потенциал $+1000 \mathrm{~V}$. Коммутация разряда происходила при напряжении на конденсаторной батарее $5.50 \mathrm{kV}$, а при $2.58 \mathrm{kV}$ разряд прерывался. На рис. 14 представлены результаты эксперимента № C0100, 500 fps с фильтром (полоса пропускания 400-500 nm).

Как и ожидалось, разряд при своем развитии стал отклоняться в сторону положительно заряженной пластины.

На рис. 14 также видна сложная динамика начального движения разряда на заряженную нержавеющую полосу, сброс заряда на нее (рис. 14,e,f) и последующее движение почти сформировавшегося плазмоида вдоль полосы, рис. 14, g. В следующем эксперименте № С0102, 500 fps камера была оборудована фильтром с полосой пропускания $400-500 \mathrm{~nm}$. Все условия эксперимента практически такие же, как в предыдущем эксперименте, только изменили полярность подвешенной полосы (полоса размером $100-270 \mathrm{~mm}$ толщиной $0.1 \mathrm{~mm}$ расположена в $75 \mathrm{~mm}$ от электрода и $75 \mathrm{~mm}$ над водой). Коммутация разряда происходила при напряжении на конденсаторной батарее $5.50 \mathrm{kV}$, а при $2.40 \mathrm{kV}$ разряд прерывался, на пластине минус (-) 1000 V. Ожидалось, что разряд будет отклоняться в противоположную сторону от отрицательно заряженной пластины (рис. 15).

На рис. 15 видим ожидаемое отклонение растущего разряда от заряженной полосы, особенности динамики развития разряда схожи с предыдущим разрядом (с разрядом на рис. 14) с учетом знака потенциала заряженной полосы. Однако в части изменения формы головки растущего разряда произошли изменения. На рис. 15 из головки выходит конус (рис. $15, f)$, который практически отсутствует в предыдущем эксперименте, рис. 14. Это связано с большим расстоянием и соответственно меньшим электрическим полем в месте „конуса“ Приведем для примера фотографии в белом свете поведения образующегося и образовавшегося плазмоида в неоднородном электрическом поле. На рис. 16 видно, что у образующегося плазмоида часть заряда вместе с частью вещества самого плазмоида образует „конус“ , в сторону усиления электрического поля (к проводу), аналогичный конусу на рис. 15. Этот конус отделяется от основного плазмоида и становится одноименным по электрическому заряду объектом, который препятствует движению основного плазмоида в том же направлении. 

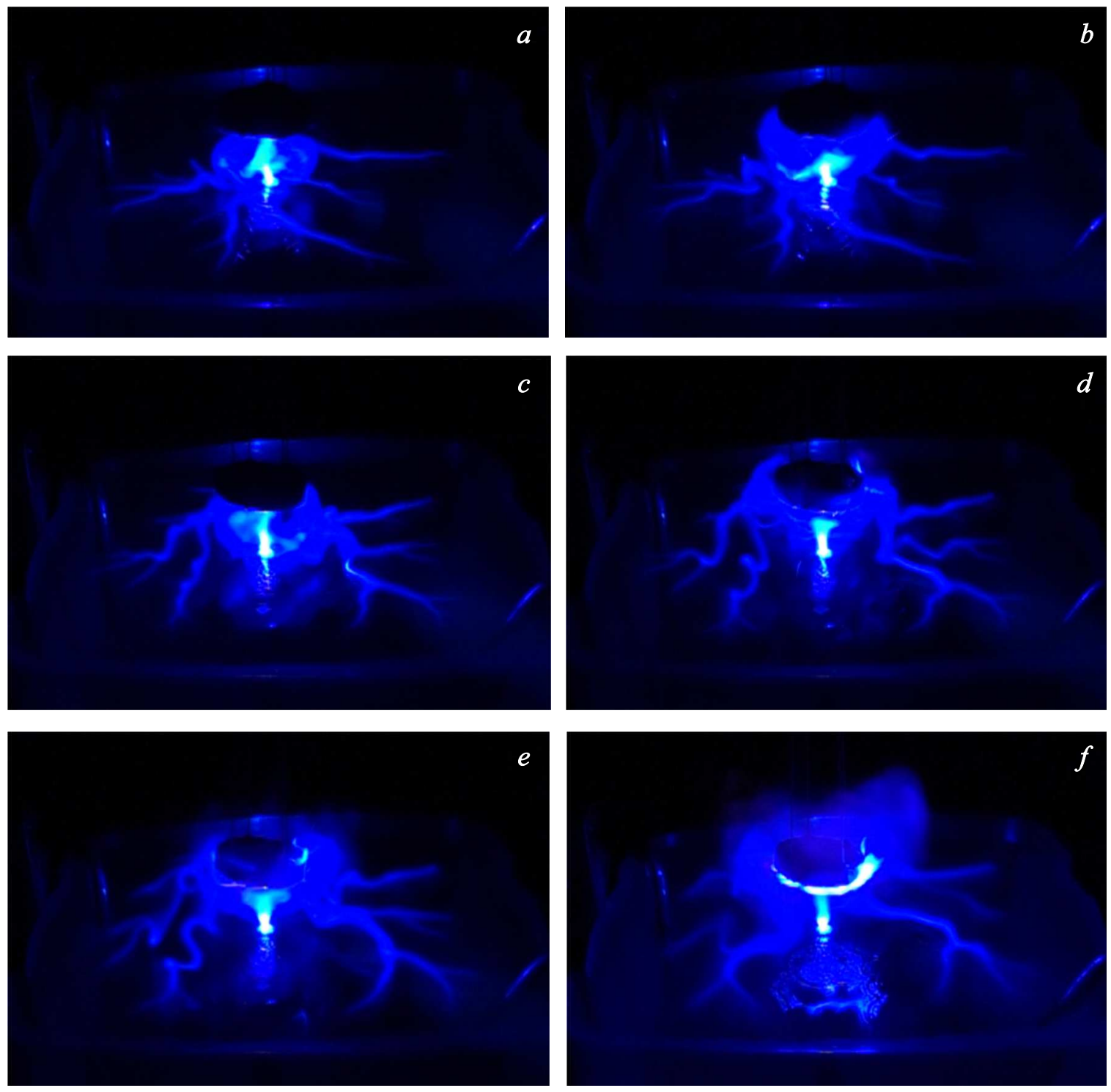

Рис. 8. Видеосъемка с фильтром, имеющим полосу пропускания 400-500 nm; кадры видеосъемки соответствуют: 3 (a), 5 ms $(b)$ разряда (эксперимент № C0139) и $5(c), 8(d), 14(e)$ и $25 \mathrm{~ms}(f)$ разряда (эксперимент № С0140).

Вышеприведенное поведение плазмоида также объясняет наблюдаемое явление гидирования шаровых молний над, например, проводами, а также вид фейерверочных шаровых молний [13]. Вид фейерверочной молнии фиксируется в тот момент, когда она при движении в неравномерном электрическом поле приближается к какой либо поверхности и, как на рис. 14-16, выбрасывает часть своего вещества вместе с электрическим зарядом, что предотвращает ее уничтожение. При сильном электрическом поле этот „защитный“ механизм не успевает сработать и, как часто наблюдается, шаровая молния „уходит“ в розетку, батарею центрального отопления, другие проводящие предметы.

Отметим также, если плазмоид имеет заряд, то его движение будет происходить на свой наведенный заряд в зеркальной проводящей плоскости. В эксперименте
№ C0110 полоса с нулевым потенциалом повешена в $140 \mathrm{~mm}$ от электрода и $75 \mathrm{~mm}$ над водой. Коммутация разряда происходила при напряжении на конденсаторной батарее $5.50 \mathrm{kV}$, а при $2.34 \mathrm{kV}$ разряд прерывался. Как и ожидалось растущий плазмоид „пошел“ в сторону пластины, а так как пластина находилась на большем расстоянии от разряда, чем в эксперименте № С0100 (и не заряжена), в связи с этим электрическое поле в месте расположения „конуса“ меньше и он лучше сформирован (рис. 17).

Динамика формирования плазмоидов в электрическом поле подтверждает существование отрицательного нескомпенсированного электрического заряда формирующихся в гатчинском разряде плазмоидов, что дополнительно подтверждает правильность инструментальных измерений заряда плазмоидов в работе [3]. 

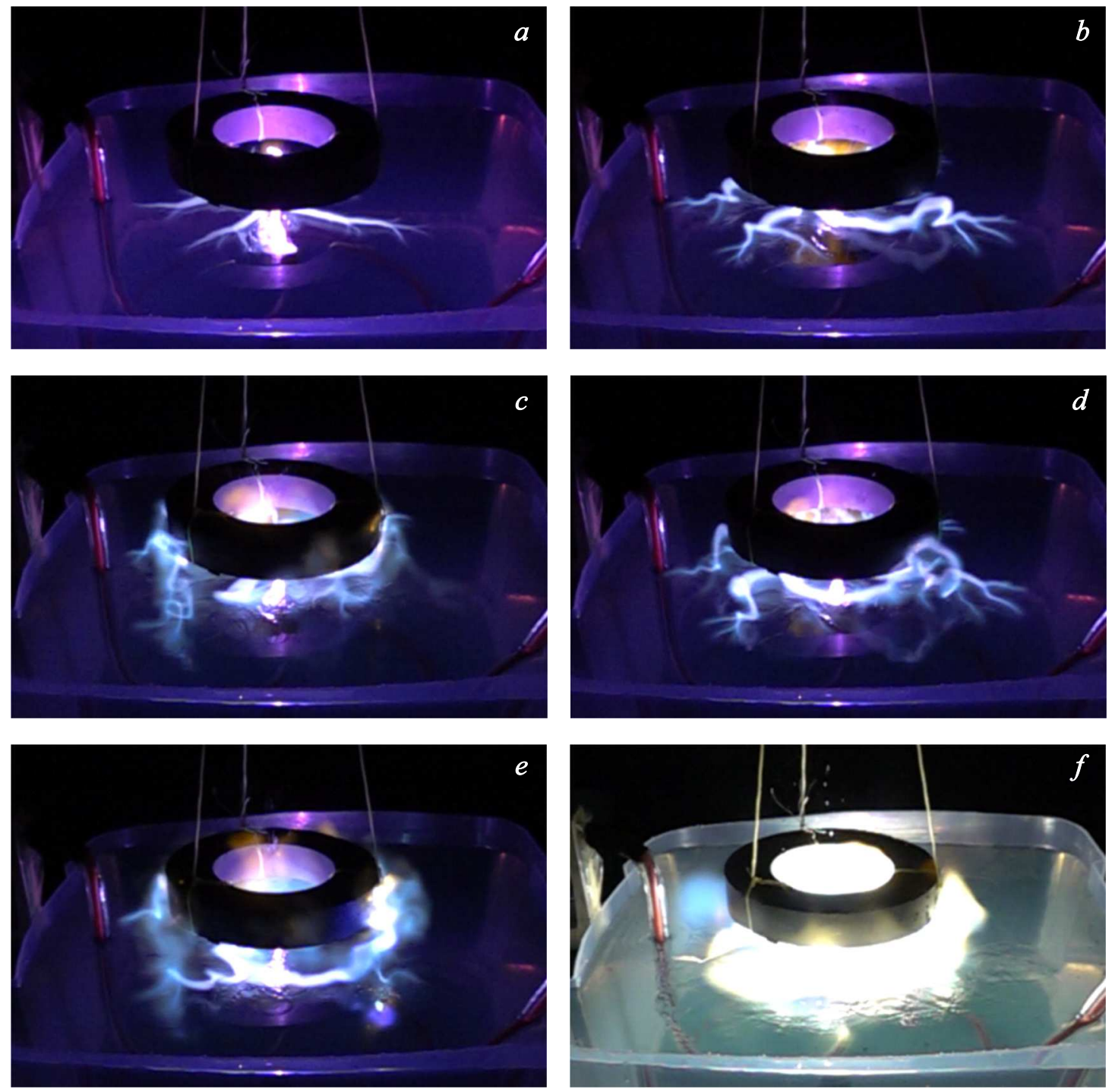

Рис. 9. Динамика развития разряда в магнитном поле кольцеобразного магнита; кадры видеосъемки соответствуют: $1(a), 4(b)$, $6(c), 10(d), 16(e)$ и $44 \mathrm{~ms}(f)$ разряда (эксперимент № C0131).

\section{4. Влияние параметров схемы на динамику формирования плазмоидов в гатчинском разряде}

В работах, исследующих гатчинский разряд, зависимость качества образующегося плазмоида от точки заземления установки почти не обсуждалась, тем интереснее показать это визуально. Предположим, что разряд коммутируется механическим способом, и при этом заземлен катод. Между контактами разрядника при разрыве соединения образуется дуга, соединяющая оба коммутирующих контакта. Процессы, происходящие в дуге, и способы ее гашения представляют собой проблему (дугу даже принимали за искусственную шаровую молнию), что рассмотрено в [1]. Приведем эксперименты №№ 1198 и 1201 (рис. 18), где в кадры видео попала дуга при коммутации разряда. В этих видео первый кадр - касание $(0 \mathrm{~ms})$, второй кадр через $33.3 \mathrm{~ms}$, и так далее через $33.3 \mathrm{~ms}$. В эксперименте № 1198 (рис. 18, $a-c$ ) коммутация разряда происходила с $5.5 \mathrm{kV}$, остаточное напряжение после отключения конденсаторных батарей $-3.84 \mathrm{kV}$. Образовалась дуга, максимальная длина которой по прямой линии между контактами разрядника $\sim 30 \mathrm{~cm}$, диаметр образовавшегося плазмоида $\sim 10 \mathrm{~cm}$. Диаметр емкости с водой составлял $20 \mathrm{~cm}$.

Эксперимент № 1201 показан на рис. 18, $d-f$. Коммутация разряда происходила с $6.0 \mathrm{kV}$, остаточное напряжение после отключения конденсаторных батарей $4.30 \mathrm{kV}$. Дуга $>30 \mathrm{~cm}$, диаметр образовавшегося плазмоида $\sim 10 \mathrm{~cm}$.

Из-за более высокого начального напряжения на конденсаторной батарее в эксперименте № 1201 при коммутации дуга была мощнее, чем в эксперименте № 1198. При заземлении катода дуга замыкает оба контактора 

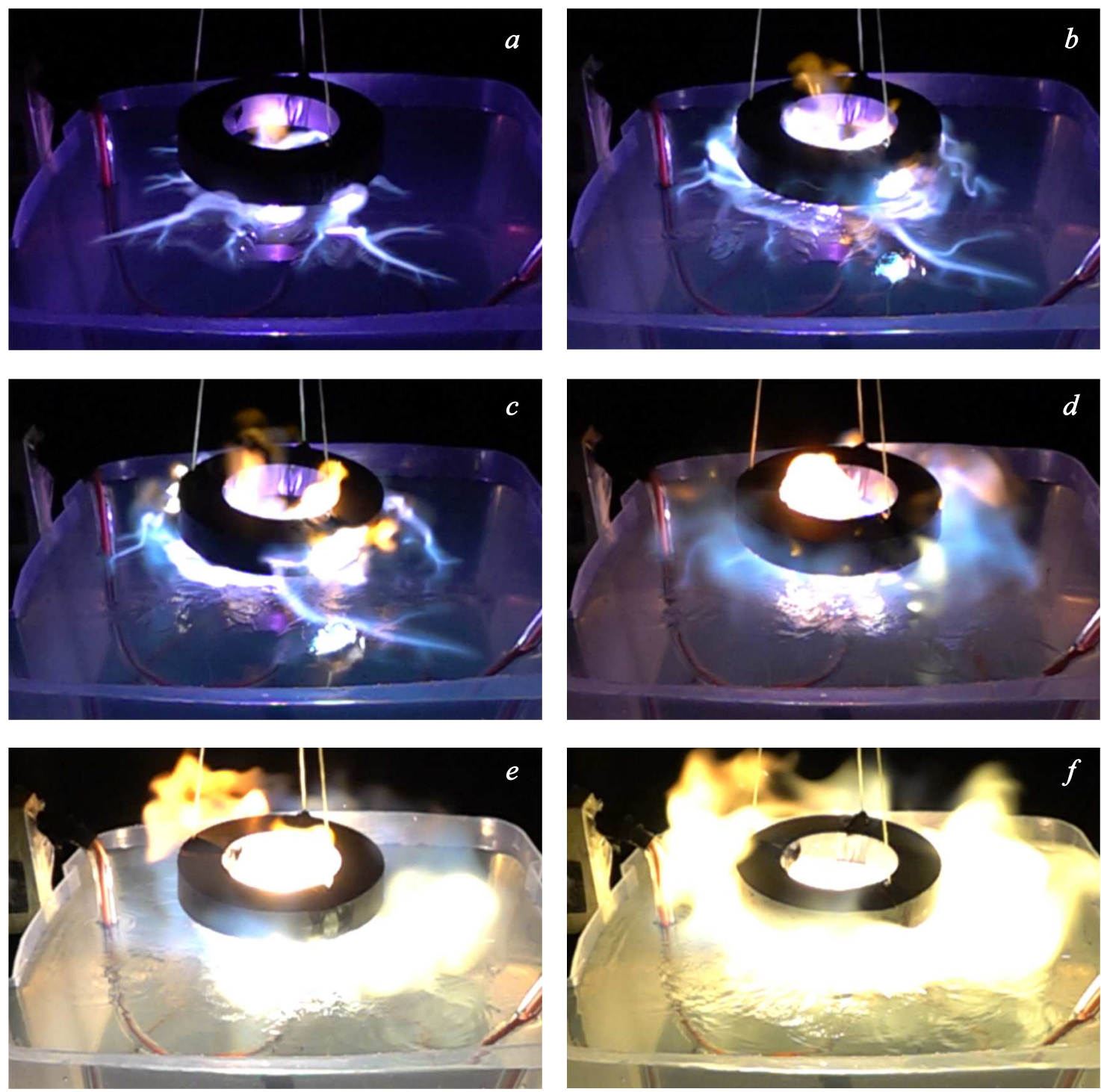

Рис. 10. Магнит имеет инверсную полярность по отношению к предыдущему эксперименту (рис. 9); кадры видеосъемки соответствуют: $3(a), 8(b), 12(c), 30(d), 50(e)$ и $70 \mathrm{~ms}(f)$ разряда (эксперимент № C0134).

разрядника, что видно на рис. 18 и на приведенных ранее рис. $14, g$ и $15, g$. Светящийся ионизированный объем воздуха в дуге сравним с объемом светящегося плазмоида. Оценку энергозапаса в плазмоиде, сделанную в работах $[14,15]$, можно экстраполировать на приведенные случаи.

При заземлении анода проблема с образованием дуги практически отсутствует. Только при чрезмерном сокращении времени коммутации образуется компактная светящаяся область у одного контактора механического разрядника, которая расположена со стороны отрицательного полюса конденсаторной батареи (рис. 19). При выполнении рекомендаций в [2] коммутация разряда при заземлении анода происходит практически без дуги, сохраняя при этом оптимальное время коммутации $\sim 80 \mathrm{~ms}$. В этом случае энергия разряда перераспреде- ляется по отношению к случаям, приведенным выше на рис. 18 , и усваивается в основном плазмоидом.

С другой стороны, казалось бы, применение плазменных коммутаторов приведет к значительному сокращению потерь энергии. Однако внесение сравнительно незначительных изменений в схему разряда (например, дополнительного небольшого активного сопротивления, емкости или индуктивности [11]) приводило к существенному изменению физики разряда. В гатчинском разряде при использовании плазменных коммутаторов вносимая ими индуктивность существенно снижает качество образующихся плазмоидов. Кроме того, по виду вольт-амперных характеристик, можно заключить, что и с регламентированием времени коммутации разряда при использовании плазменных коммутаторов возникают проблемы, а длительность первой фазы разряда - 

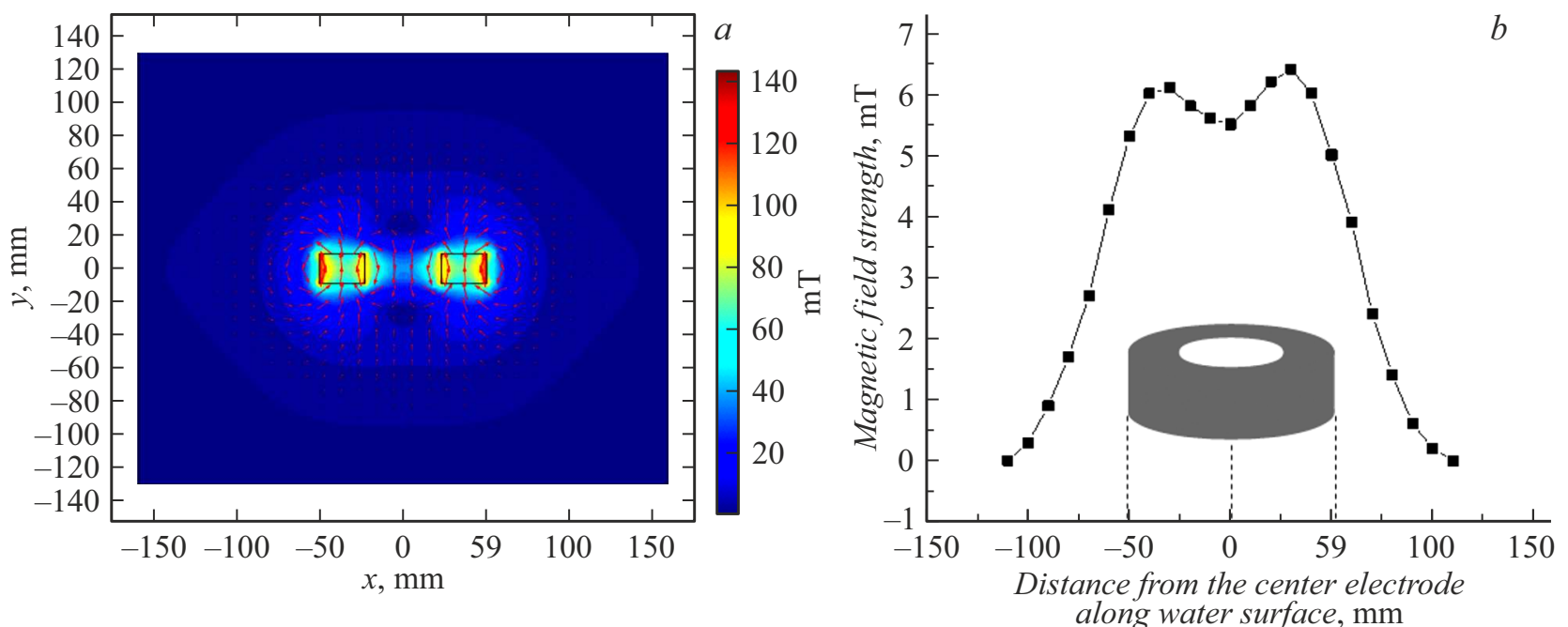

Рис. 11. $a-$ интенсивность магнитного поля кольцеобразного магнита; $b-$ интенсивность магнитного поля на поверхности воды.
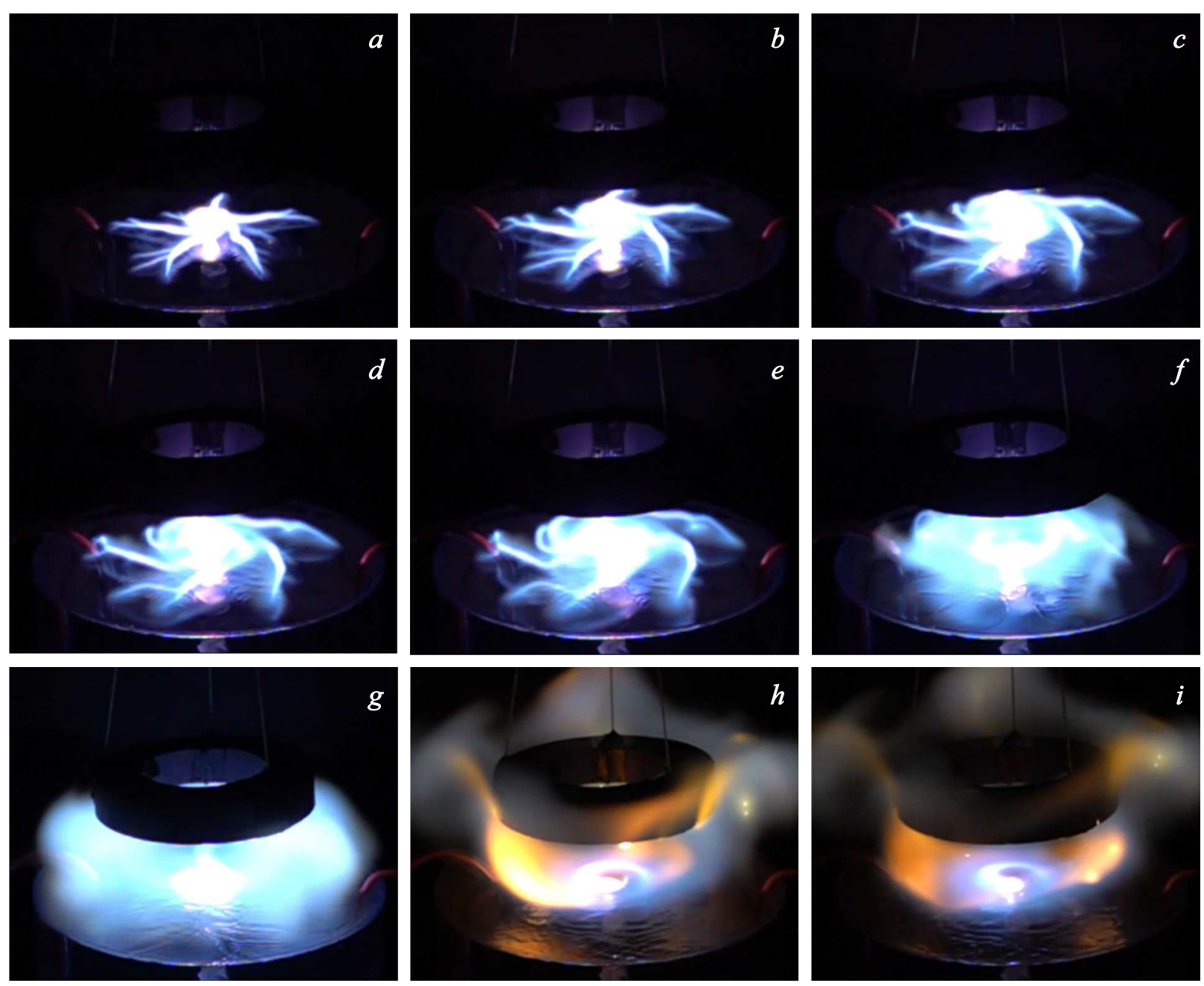

Рис. 12. Динамика развития разряда в магнитном поле кольцеобразного магнита. Лидерно-стримерная система вращается в левую сторону. Кадры видеосъемки соответствуют: $1(a), 2(b), 3(c), 4(d), 5(e), 10(f), 30(g), 71(h)$ и 80 ms $(i)$ разряда (эксперимент № C0177). 

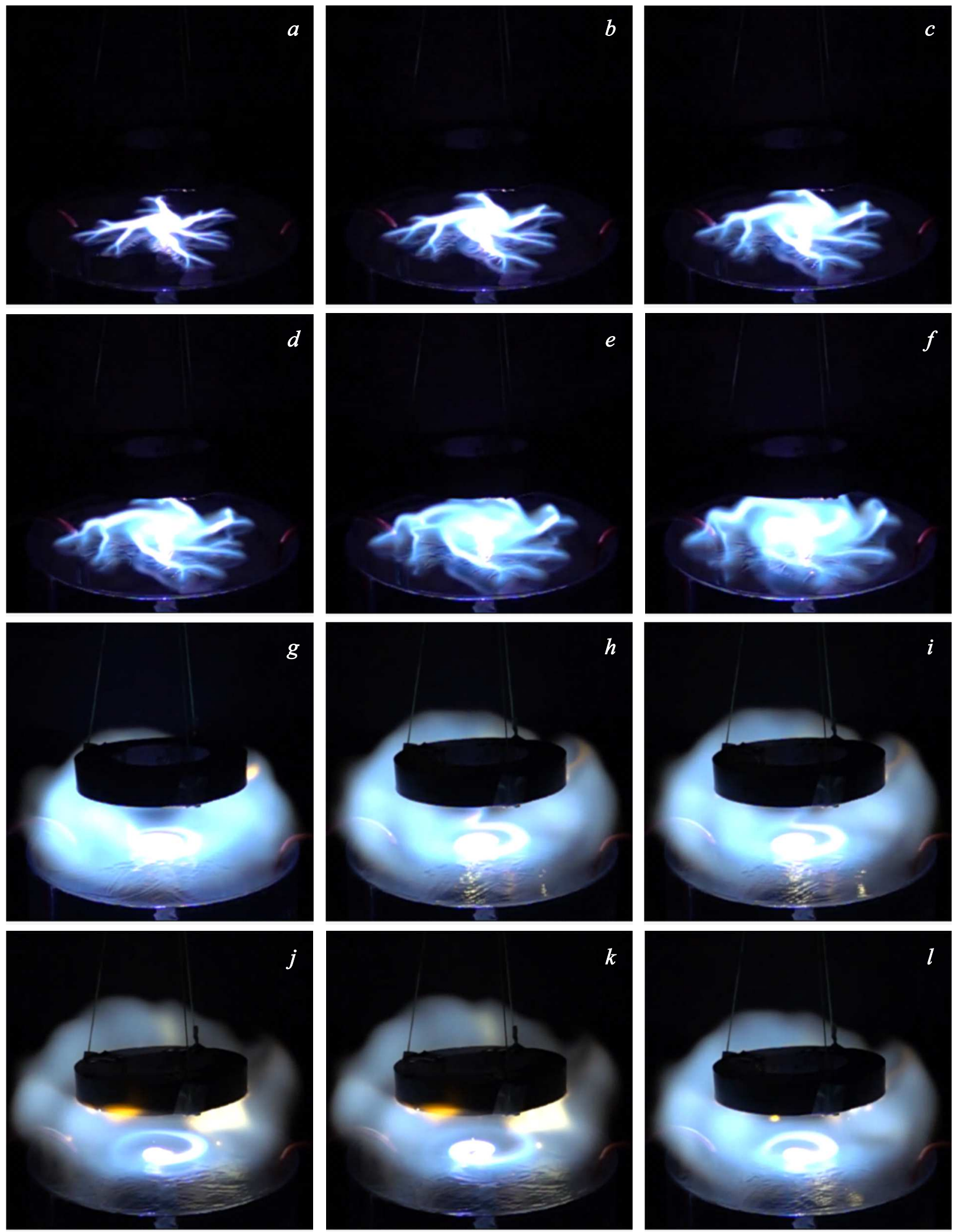

Рис. 13. Вращение лидерно-стримерной системы в правую сторону в магнитном поле кольцеобразного магнита. Кадры видеосъемки соответствуют: $1(a), 2(b), 3(c), 4(d), 5(e), 7(f), 31(g), 40(h), 42(i), 46(j), 53(k)$ и 54 ms $(l)$ разряда (эксперимент № C0178). 


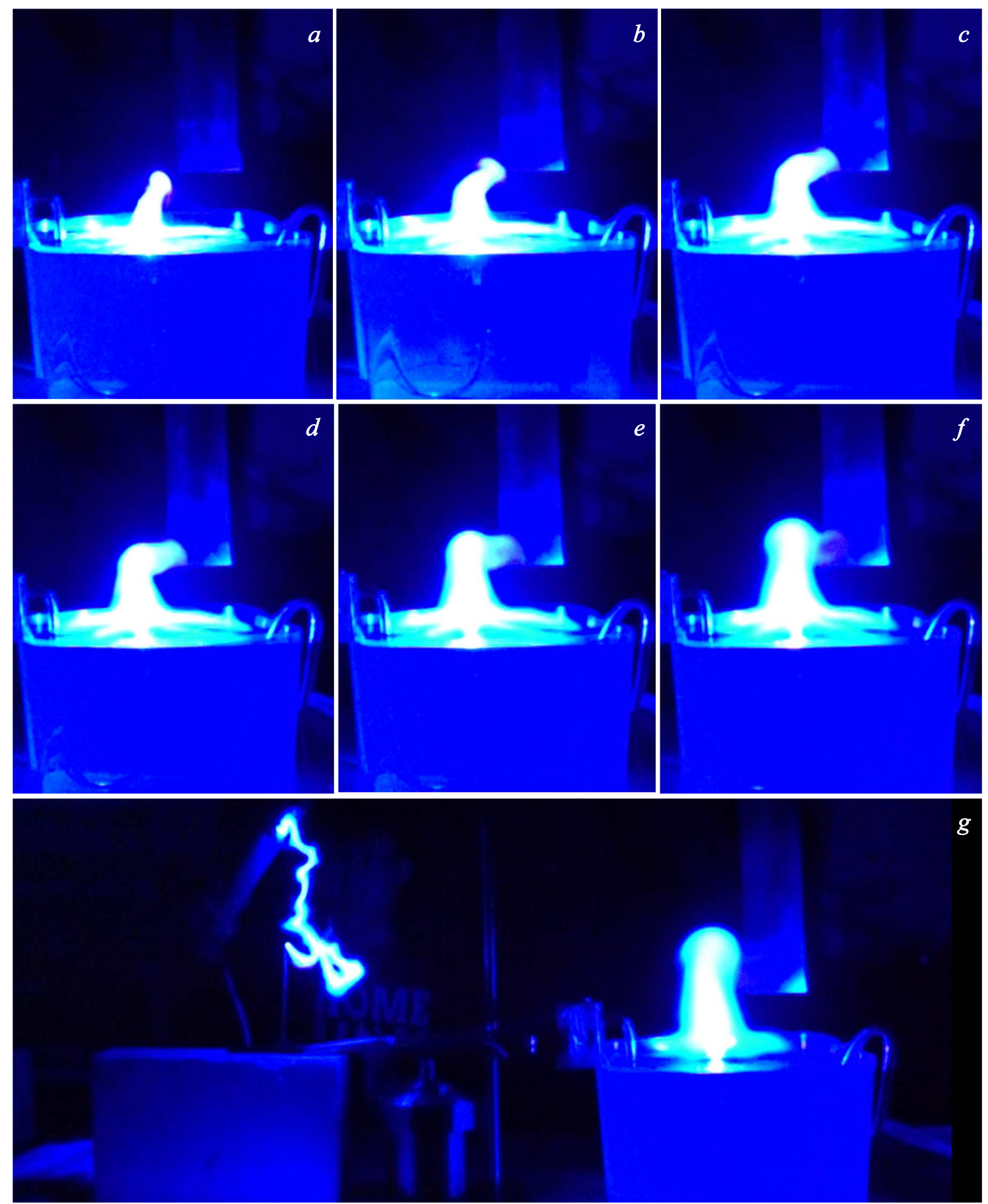

Рис. 14. Динамика движения образующегося плазмоида в сторону положительно заряженной пластины. Кадры видеосъемки соответствуют: $10(a), 20(b), 32(c), 38(d), 48(e), 60(f)$ и $82 \mathrm{~ms}(g)$ разряда (эксперимент № C0100).

один из основных параметров, влияющих на продолжительность свечения плазмоида.

\section{Обсуждение и выводы}

Рассмотренные эксперименты в настоящей работе самым тесным образом связаны с установлением при- роды шаровой молнии. В России к вопросам о шаровой молнии проявляли интерес нобелевские лауреаты В.Л. Гинзбург и П.Л. Капица $[16,17]$, вероятно в надежде за феноменом существования шаровой молнии открыть дотоле неизвестные физические закономерности. Гатчинский разряд [18], в котором предположительно создается аналог шаровой молнии, был смоделирован из анализа работ [19-22]. Аналог по размеру и светимости соот- 

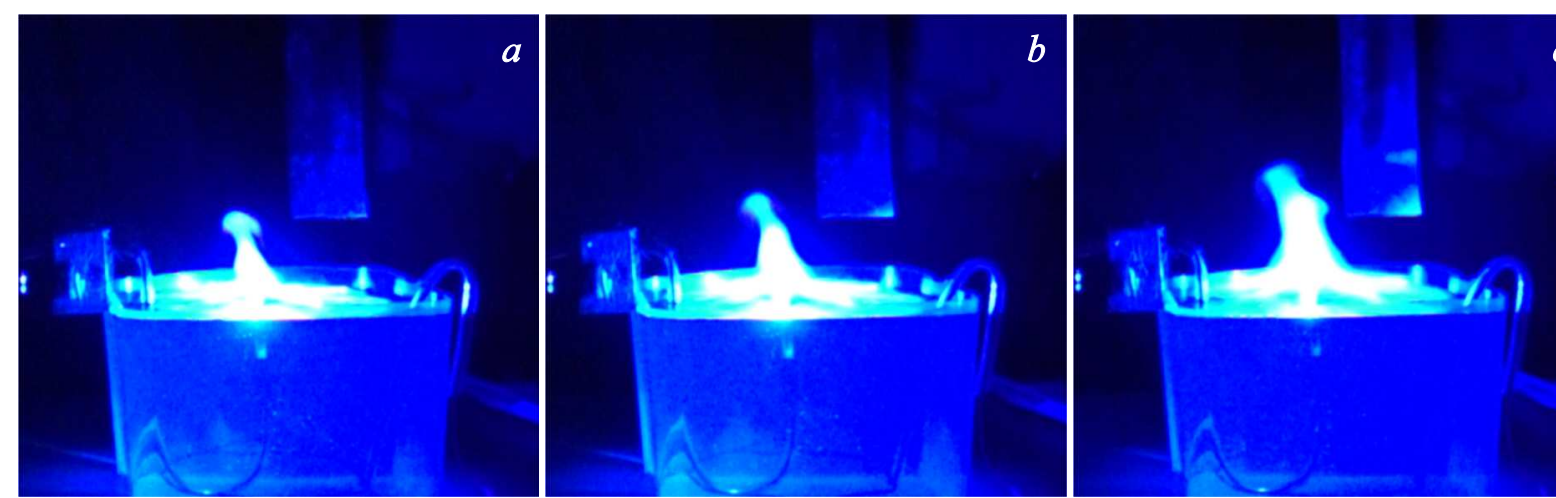

$c$
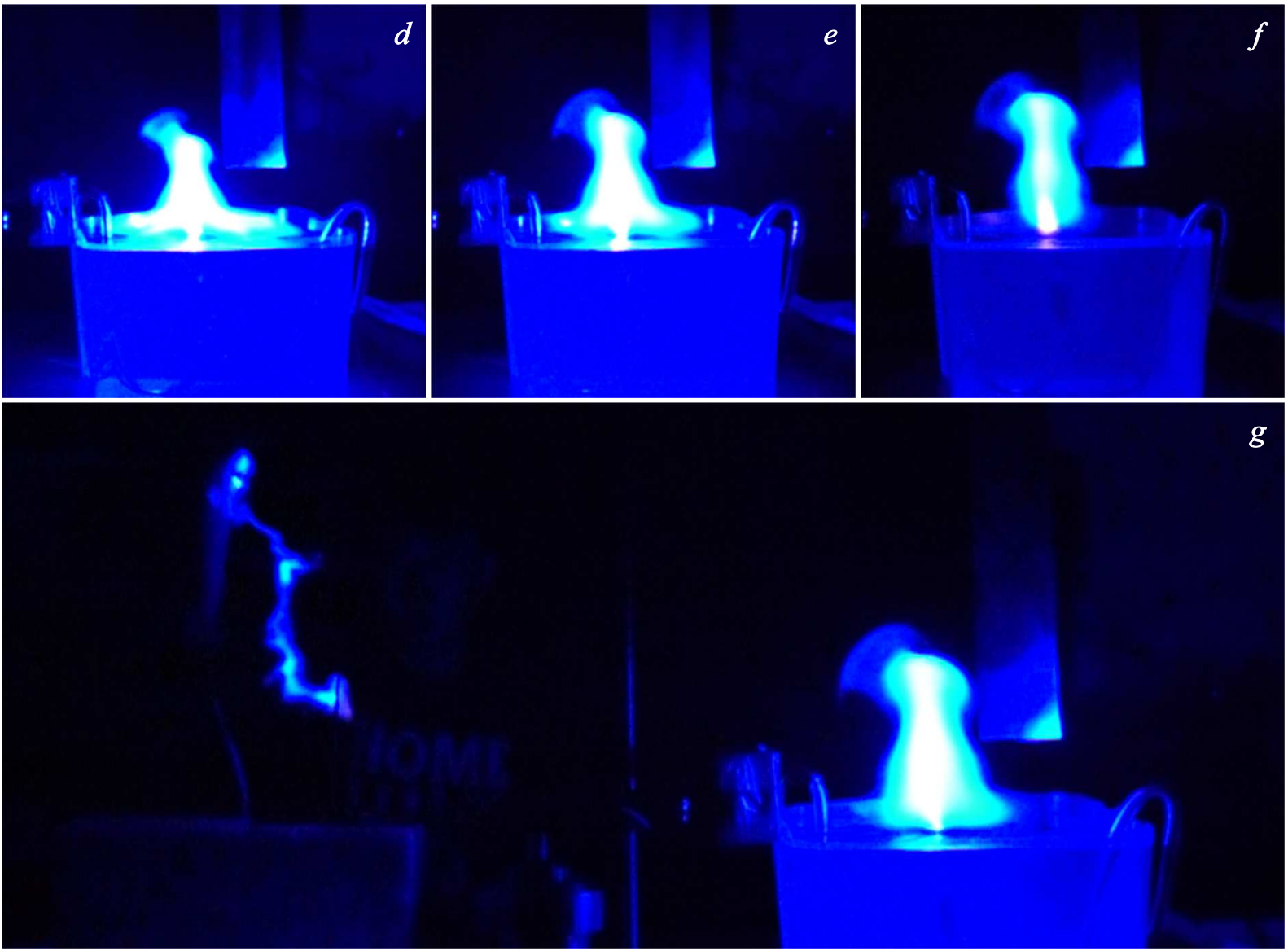

Рис. 15. Движение образующегося плазмоида в противоположную от отрицательно заряженной пластины сторону. Кадры видеосъемки соответствуют: $12(a), 20(b), 40(c), 56(d), 80(e), 106(f)$ и $92 \mathrm{~ms}(g)$ разряда (эксперимент № C0102).

ветствовал наиболее часто наблюдаемой природной шаровой молнии диаметром $12-15 \mathrm{~cm}[23]$, в то время как в [19-22] это были струи, вырывающиеся из плазмотрона (струя Авраменко) или в лучшем случае автономные „бусинки“ размером 5-6 mm.

Близость „аномальных“ свойств объектов, наблюдаемых в $[19,20]$ и гатчинском разряде, позволяет предположить схожесть физики их рождения. В $[19,20]$ или его модификациях [21,22] ни один из электродов не покрыт диэлектриком (в отличие от гатчинского разряда), но в процессе разряда второй электрод оказывается изолированным от разрядных процессов мощной пре- градой из испаряющегося полиметилметакрилата или паров стеарина. То есть оба разряда имеют признаки барьерного разряда, но гатчинский разряд к тому же приобрел свойства поверхностного разряда (см., например, [24]), который называется также скользящим или плазменным листом [25]. Гатчинский разряд, имеющий как элементы незавершенного барьерного, так и скользящего разряда, формирует на поверхности воды плазменный лист, причем, поскольку в разряде не пробивается разрядный промежуток и поэтому отсутствует сильноточная фаза, образующийся плазменный лист обладает высокой однородностью. Ток незавершен- 

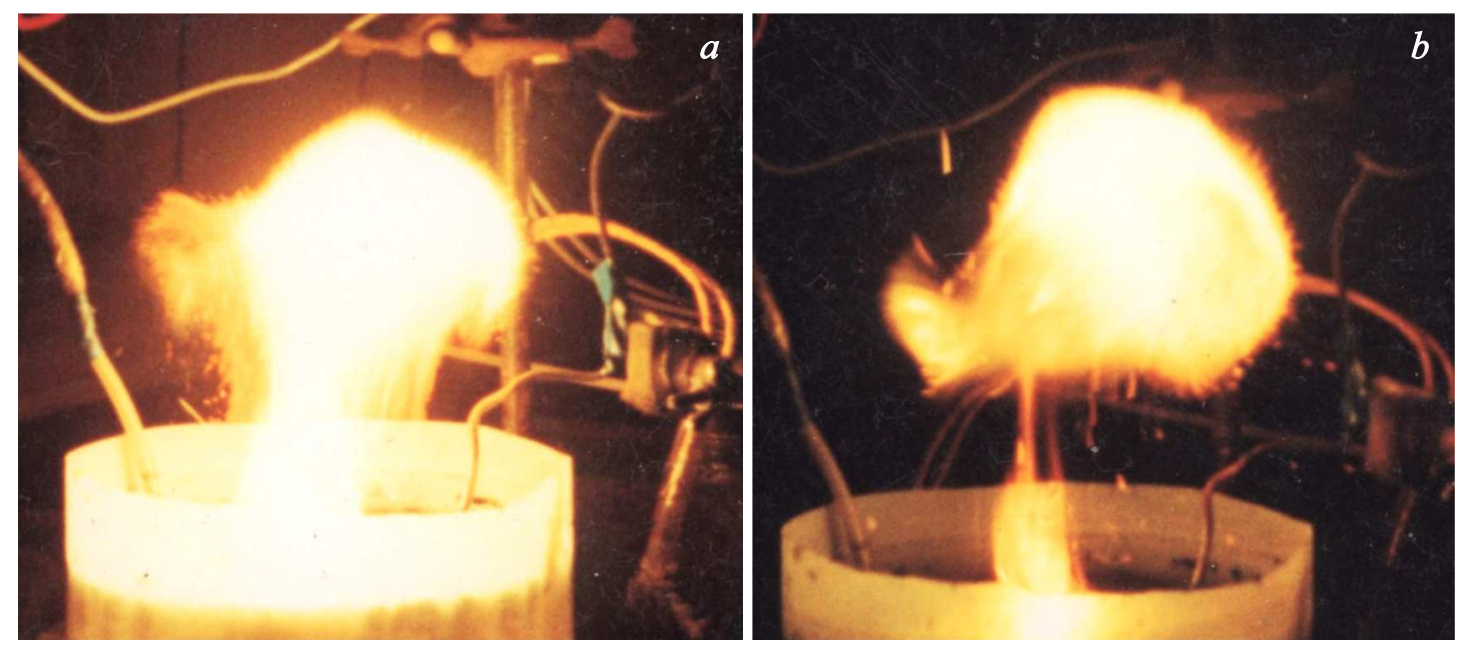

Рис. 16. Динамика формирования плазмоида в электрическом поле проводника, имеющего нарушение изоляции; $a-$ плазмоид в неоднородном электрическом поле образует „конус“, направленный в сторону положительно заряженного проводника; $b-$ заряженный одноименно с плазмоидом „конус“ обосабливается и изменяет направление движения основного плазмоида в противоположную от проводника сторону.
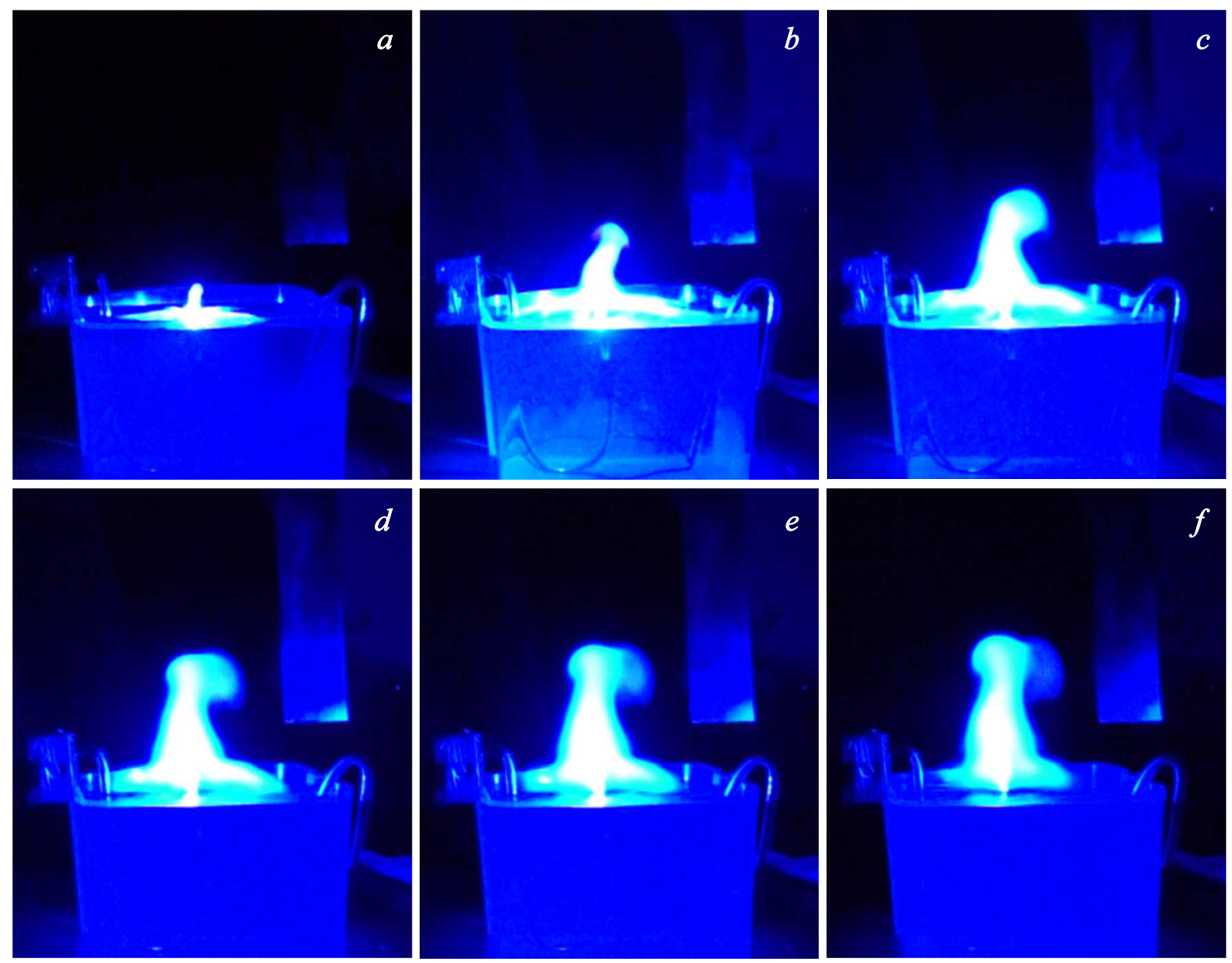

Рис. 17. Движение формирующегося плазмоида на наведенный заряд в проводящей плоскости. Кадры видеосъемки соответствуют: $0(a), 20(b), 50(c), 70(d), 80(e)$ и $90 \mathrm{~ms}(f)$ разряда (эксперимент № C0110). 


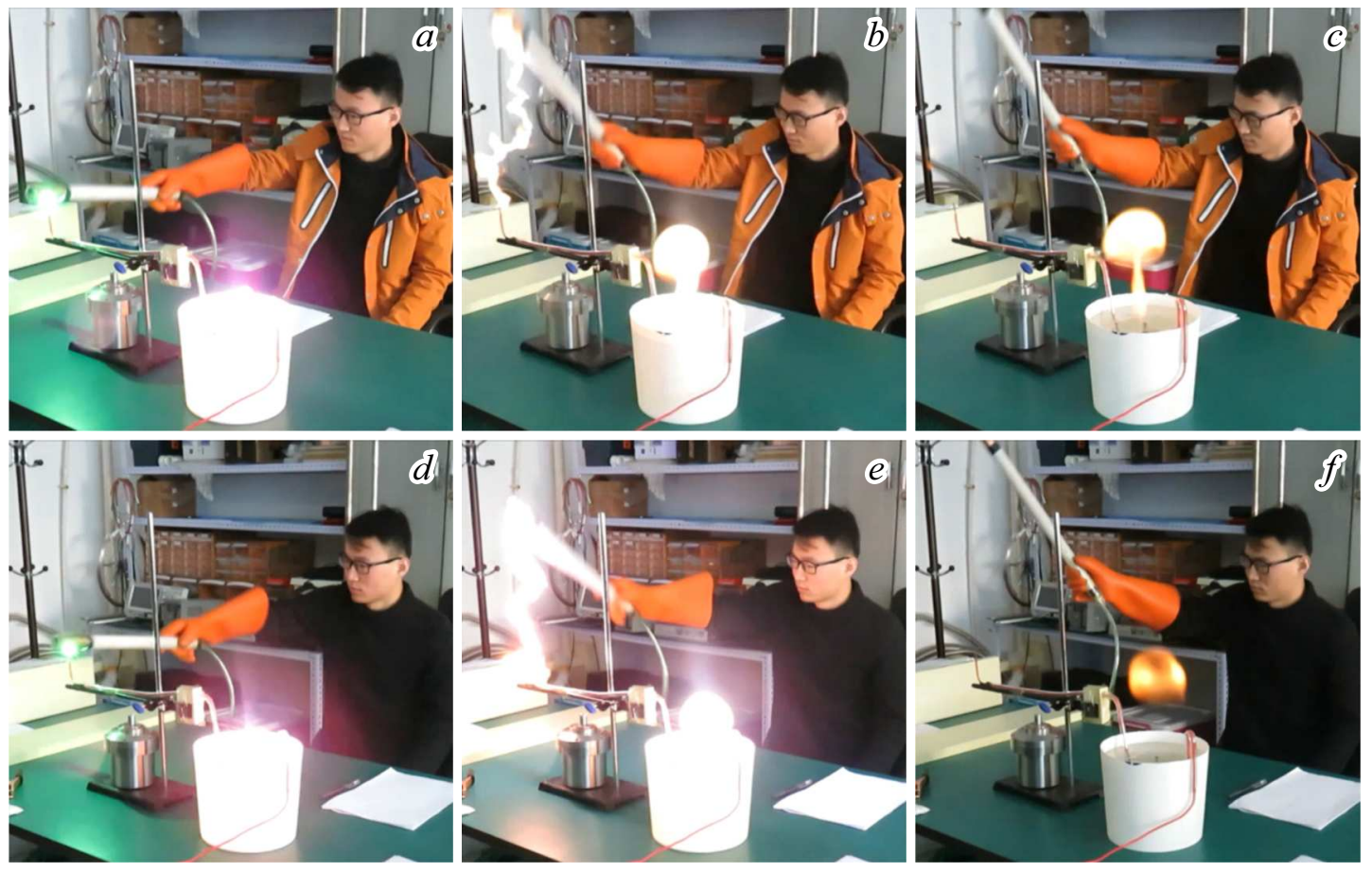

Рис. 18. Дуга при коммутации разряда. Кадры видеосъемки соответствуют: $0(a), 133.3$ (b), 166.6 ms (c) разряда (эксперимент № 1198) и $0(d), 100(e)$ и $200 \mathrm{~ms}(f)$ разряда (эксперимент № 1201).

ного скользящего/барьерного разряда ограничивается распределенной емкостью диэлектрической подложки и равен $I=U(\partial C / \partial t)+C(\partial U / \partial t)$, где $U-$ приложенное к электродам напряжение, $C$ - емкость промежутка, который образован листовой плазмой и электродом, отделенным от плазмы диэлектриком. После наполнения поверхности диэлектрика плазмой (в этот момент коммутация гатчинского разряда должна быть прекращена) ток незавершенного скользящего разряда определяется только вторым слагаемым (ток смещения). Если не прекратить разряд, то ток смещения продолжит греть плазму и температура ее может достичь $(2-3) \cdot 10^{3} \mathrm{~K}[24,25]$, в связи с чем свойства образующегося плазмоида ухудшатся или он будет полностью уничтожен. Поэтому так важна оптимальная продолжительность разряда. Природа скользящего разряда связана с наличием двух различных диэлектрических сред - газа и диэлектрика, способствующих созданию нормальной составляющей электрического поля при одновременном развитии разряда в тангенциальном направлении. В результате имеется возможность создания достаточно однородных плазменных поверхностей больших размеров с нескомпенсированным электрическим зарядом, что подтверждается, в частности, моделированием и сравнением результатов моделирования с экспериментальными данными процесса развития разряда вдоль поверхности диэлектрика $[4,5]$.

Сочетание неожиданных физико-технических решений в гатчинском разряде позволило сохранить (наследовать) в образующихся в нем плазмоидах структуру и особые свойства „бусинок“ из разряда Авраменко [3]. Кроме очевидных свойств разрядов типа Авраменко, в работе [22], например, измерялась скорость звука при прохождении его по стержню (при пониженном давлении атмосферы струя Авраменко превращалась в стержень 2-3 m длиной), которая оказалась $\sim 1600 \mathrm{~m} / \mathrm{s}$. Скорость ультразвука также была измерена „непосредственно“ в гатчинском плазмоиде и оказалась равной $\sim 1400 \mathrm{~m} / \mathrm{s}$ [26]. По этим данным расчетная температура плазмоида оценивается в $2000 \mathrm{~K}$ и более. Однако температура плазмоида, оцененная в других работах [27,28], оказалась на порядок ниже. В связи с этим отметим, что в [22,26-28] один и тот же параметр (температура) оценен исходя из одной модели, но его значение различается более чем на порядок из-за различных инструментальных методов измерений и сопровождающих эти измерения физико-математических моделей, см., например, $[2,3,26]$. Это говорит о том, что как сам разряд, так и образующиеся в нем плазмоиды требуют для своего исследования разностороннего подхода, различных экспериментальных методик, опирающихся на различные модельные представления.

В нашей модели плазмоид диаметром, как правило, около $12 \mathrm{~cm}$, несет значительный нескомпенсированный электрический заряд $\left(4 \cdot 10^{-6} \mathrm{C}\right.$ в момент отрыва плазмоида от электрода, $4 \cdot 10^{-7} \mathrm{C}$ через $110 \mathrm{~ms}$ после отрыва от электрода и т.д.), который измерялся, оценивался, исходя из разных модельных представлений, что подробно рассмотрено в [2]. Это не очевидно для ряда исследователей, например [6,7]. Изменение авторской 

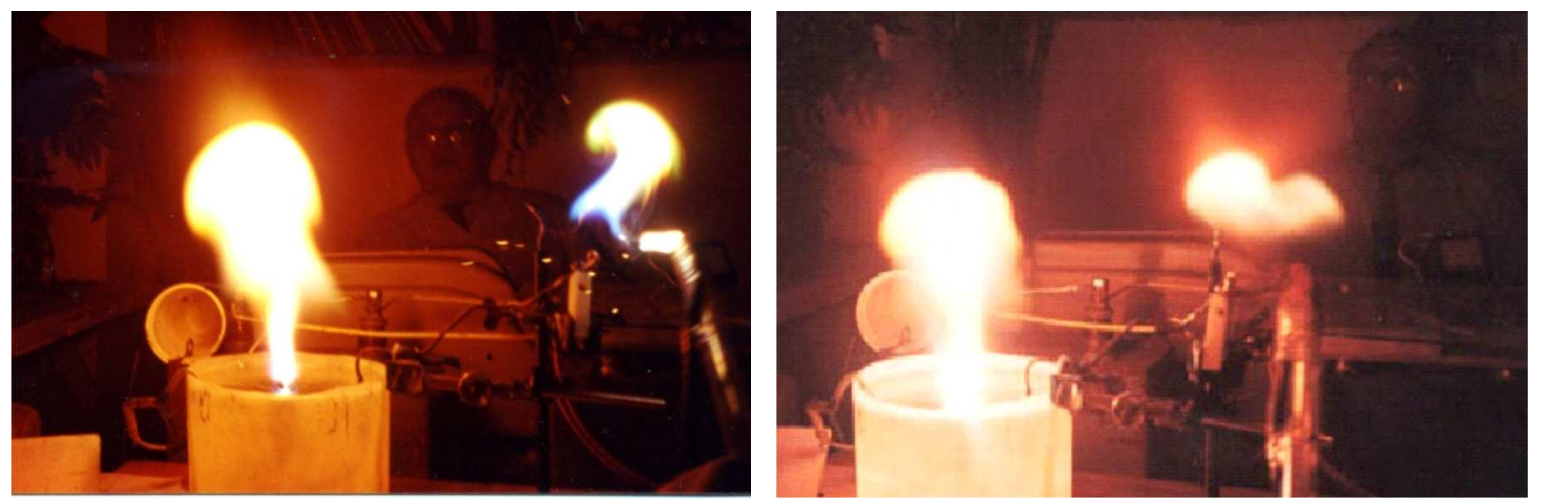

Рис. 19. Варианты образования второго светящегося образования с медной коммутирующей штанги (в правой половине кадров) при сокращенном времени коммутации до $\sim 50 \mathrm{~ms}$.

схемы разряда, как то изменение точки заземления установки, ведет к отсутствию заряда у образующегося плазмоида, см. например, [26]. Однако небольшой заряд может присутствовать у плазмоидов, полученных при заземлении центрального электрода при соблюдении всех прочих условий его создания [2]. В противном случае, если, например, в дополнение к заземлению центрального электрода, увеличить время коммутации $(140 \mathrm{~ms}$ в [26]), то у плазмоида будет отсутствовать нескомпенсированный заряд. Отсутствие или малая величина нескомпенсированного заряда определяется по увеличению диаметра плазмоида (в 2-3 раза) в процессе его всплытия [6,7]. Плазмоиды с зарядом сохраняют свой диаметр вплоть до его исчезновения [2].

В настоящей работе было показано, что нескомпенсированный заряд существует в теле лидеров и подается в будущий плазмоид. Возникающие трудности для демонстрации этого эффекта при работе с магнитами описаны выше.

В целом эксперименты по наблюдению поведения лидерно-стримерной системы и плазмоидов в магнитных и электрических полях показали способ доставки нескомпенсированного заряда и удержание его в плазмоиде.

Ранее было отмечено [29], что только при отрицательной полярности центрального электрода достигались лучшие результаты при воспроизведении плазмоида. Подробно вопрос о влиянии полярности центрального электрода рассмотрен в [30], где предполагается дальнейшее исследование процессов как при отрицательной, так и при положительной полярности центрального электрода. Также в [30] был рассмотрен вопрос о форме центрального электрода, были получены плазмоиды с плоского центрального электрода и отмечено, что добавление воды на электрод не является необходимой процедурой для получения долгоживущих плазмоидов, что ранее в [2] также отмечалось. Противоположное мнение, например в [31], состояло в том, что при добавлении воды на электрод создаются высокоэнергетические радикалы, которые способствуют более длитель- ному свечению плазмоидов. Возвращаясь к заземлению, отметим, что инструментальные измерения показали ([26] и ссылки в этой работе), что при заземлении центрального электрода нескомпенсированный заряд в плазмоиде отсутствует. В настоящей работе с привлечением более ранних экспериментов (рис. 19) качественно показано, что мощное дугообразование (рис. $18,14, g$ и $15, g)$ в случае заземления центрального электрода ведет к значительному снижению подвода энергии к плазмоиду.

Как теоретические [32], так и теоретико-экспериментальные модели [33] плазмоида оказываются полезными для постановки экспериментов. Измерения в инфракрасном диапазоне в [33] показали, что плазмоид превращается в тор и стабилен более, чем в течение $1.5 \mathrm{~s}$. В свою очередь, автор [18] визуально наблюдал длительное существование плазмоида $(\sim 2 \mathrm{~s})$. Плазмоид поднимался на высоту $3.6 \mathrm{~m}$ (потолок $3.8 \mathrm{~m}$ минус $0.2 \mathrm{~m}$ - размер воздухозаборника), ударялся о плоскую поверхность воздухозаборника и отскакивал назад, после чего распадался. Это возможно при использовании $\mathrm{Cu}-\mathrm{Si}$-электрода. Электрод выдерживал 2-3 выстрела, после чего его требовалось заменять, в связи с этим эксперименты с этим электродом больше не проводились.

Следует отметить, что существующие модели плазмоида не отличаются разнообразием и сложностью.

В заключение выскажемся о предлагаемой нами гипотезе построения плазмоида. В этой модели основным энергетическим резервуаром является электрическое поле, создаваемое электрическими зарядами, левитирующими у внутренней поверхности оболочки плазмоида [3,34]. Гатчинский плазмоид при заряде $4 \cdot 10^{-6} \mathrm{C}$ и диаметром около $12 \mathrm{~cm}$ запасает энергию $1 \mathrm{~J}$ (расчет и оценка энергии по выделившейся энергии при расплавлении нихромовой проволоки [2]). Заряды имеют относительно большую плотность и могут представлять собой неидеальную плазму с ближним порядком, которая взаимодействует с оболочкой $[3,35]$. 
Также полезными для понимания физических процессов в шаровых молниях и плазмоидах являются достаточно сложные модели, представленные в рабо$\operatorname{Tax}[32,36]$.

\section{Благодарности}

Авторы признательны А.Г. Крившичу и О.М. Жеребцову за полезные замечания, высказанные при подготовке настоящей работы.

\section{Конфликт интересов}

Авторы заявляют, что у них нет конфликта интересов.

\section{Список литературы}

[1] Shixin Zhao, Chengxun Yuan, A.A. Кудрявцев, O.M. Жеребцов, Г.Д. Шабанов. ЖТФ, 91 (7), 1108 (2021). DOI: 10.21883/JTF.2021.07.50952.342-20 [Shixin Zhaoa, Chengxun Yuana, A.A. Kudryavtsev, O.M. Zherebtsov, G.D. Shabanov. Tech. Phys., 66 (7), 1081 (2021). DOI: $10.1134 / \mathrm{S} 1063784221070173]$

[2] Г.Д. Шабанов. УФН, 189 (1), 95 (2019). [G.D. Shabanov. Physics-Uspekhi, 62 (1), 92 (2019). DOI: $10.3367 /$ UFNe.2018.03.038318]

[3] Г.Д. Шабанов, Б.Ю. Соколовский. Физика плазмы, 31 (6), 560 (2005). [G.D. Shabanov, B.Yu. Sokolovskiy. Plasma Phys. Reports. 31 (6), 512 (2005).]

[4] В.Р. Соловьев, А.М. Кончаков, В.М. Кривцов, Н.Л. Александров. Физика плазмы, 34 (7), 648 (2008). [V.R. Solov'ev, A.M. Konchakov, V.M. Krivtsov, N.L. Aleksandrov. Plasma Phys. Reports, 34 (7), 594 (2008).]

[5] Л.А. Жиляков, А.В. Костановский, Г.П. Похил. ТВТ, 46 (5), 786 (2008). [L.A. Zhilyakov, A.V. Kostanovskii, G.P. Pokhil. High Temperature, 46 (5), 721 (2008).]

[6] B. Juettner, S. Noack, A. Versteegh, G. Fussmann. 28th Intern. Conf. on Phenomena in Ionized Gases (28th ICPIG), July 15-20, 2007, Prague, Czech Republic, WA6. 5P12-05, 2229 (2007).

[7] A. Versteegh, K. Behringer, U. Fantz, G. Fussmann, B.J. Uttner, S. Noack. Plasma Sources Sci. Technol., 17, 024014 (2008). DOI: 10.1088/0963-0252/17/2/024014

[8] M. Jacobs, W. Gekelman, P. Pribyl, Y. Qian, S. Abarzhi. Phys. Plasmas, 28, 052114 (2021). DOI: 10.1063/5.0040880

[9] Э.М. Базелян, Ю.П. Райзер. УФН, 170 (7), 753 (2000). [E.M. Bazelyan, Yu.P. Raizer. Phys. Usp., 43, 701 (2000)].

[10] E.M. Bazelyan, Yu.P. Raizer. Lightning Physics and Lightning Protection (Institute of Physics Publ., Bristol, 2000) [Пер. с англ. Э.М. Базелян, Ю.П. Райзер. Физика молнии и молниезащиты (Физматлит, М., 2001)]

[11] В.В. Пантелеев, С.С. Васильев. Исследование возбуждения молекул в холодных импульсных электроразрядах. Tp. 1-й межвузовской конференщии по химии и физике низкотемпературной плазмы (Изд-во МГУ, М., 1971), c. 153-155. [V.V. Panteleev, S.S. Vasiliev. Proceedings of the 1st Interuniversity Conference on Chemistry and Physics of Low-Temperature Plasma. (Publishing house of Moscow State University, M.,1971), p. 153-155.]
[12] К.Л. Корум, Дж.Ф. Корум. УФН, 160 (4), 47 (1990). [J.F. Corum, K.L. Corum. Physics. Uspekhi, 33 (4), (1990).]

[13] Дж. Барри. Шаровая молния и четочная молния (Мир, M., 1983) [J.D. Barry. Ball Lightning and Bead Lightning (Plenum, NY., 1980)]

[14] U. Fantz, S. Kalafat, R. Friedl, S. Briefi. J. Appl. Phys., 114 (4), 043302 (2013). http://dx.doi.org/10.1063/1.4816311

[15] U. Fantz, R. Friedl, S. Briefi. J. Appl. Phys., 117 (17), 173301 (2015). http://dx.doi.org/10.1063/1.4919607

[16] В.Л. Гинзбург. УФН, 169 (4), 419 (1999). [V.L. Ginzburg. Phys. Usp., 42, 353 (1999).]

[17] П.Л. Капица. ДАН, 101 (2), 245 (1955). [P.L. Kapitza. Doklady Akad. Nauk S.S.S.R., 101 (2), 245 (1955).]

[18] Г.Д. Шабанов. Письма в ЖТФ, $28(4), 81$ (2002). [G.D. Shabanov. Tech. Phys. Lett., 28 (2), 164 (2002).]

[19] Р.Ф. Авраменко, Б.Н. Бахтин, В.И. Николаева, Л.П. Поскачеева, Н.Н. Широков. ЖТФ, 60 (12), 57 (1990). [R.F. Avramenko, B.I. Bakhtin, V.I. Nikolaeva, L.P. Poskacheeva, N.N. Shirokov. Soviet Physics. Tech. Phys., 35 (12), 1396 (1990).]

[20] Р.Ф. Авраменко, В.И. Николаева, Л.П. Поскачеева. Шаровая молния в лаборатории. Сб. статей (Химия, M., 1994), c. 15-56. [R.F. Avramenko, V.I. Nikolaeva, L.P. Poskacheeva. Collection of Articles (Khimiya, M., 1994), p. $15-56$.]

[21] С.Е. Емелин, В.С. Семенов, А.И. Эйхвальд, А.К. Хассани. Шаровая молния в лаборатории. Сб. статей (Химия, М., 1994), c. 87-95. [S.E. Emelin, V.S. Semenov, A.I. Eyhvald. Collection of Articles (Khimiya, M., 1994), p. 87-95.]

[22] А.И. Климов, Г.И. Мишин. Письма в ЖТФ, 19 (13), 19 (1993). [A.I. Klimov, G.I. Mishin. Tech. Phys. Lett., 19, 405 (1993).

[23] И.П. Стаханов. О физической природе шаровой молнии (Мир, М., 1996), 3-е изд. [I.P. Stakhanov. The Physical Nature of Ball Lightning (Atomizdat, M., 1979)]

[24] А.Н. Григорьев, А.В. Павленко, А.П. Ильин, Е.И. Карнаухов. Известия Томского политех. ун-та, $309(1), 66$ (2006).

[25] Г.П. Кузмин, И.М. Минаев, А.А. Рухадзе. ТВТ, 40 (3), 515 (2002). [G.P. Kuz'min, I.M. Minaev, A.A. Rukhadze. High Temperature, 40, 477 (2002).]

[26] С.И. Степанов. ЖТФ, 84 (1), 109 (2014). [S.I. Stepanov. Tech. Phys., 59 (1), 107 (2014).]

[27] Г.Д. Шабанов, А.Г. Крившич, Б.Ю. Соколовский, О.М. Жеребцов. Физика плазмы, 35 (7), 665 (2009). [G.D. Shabanov, A.G. Krivshich', B.Yu. Sokolovski, O.M. Zherebtsov. Plasma Phys. Reports, 35 (7), 611 (2009).]

[28] А.И. Егоров, С.И. Степанов. ЖТФ, 72 (12), 102 (2002). [A.I. Egorov, S.I. Stepanov. Tech. Phys., 47 (12), 1584 (2002).]

[29] М.И. Баранов. Электротехника и электромеханика. 5, 56 (2013). [M.I. Baranov. Electrical Engineering \& Electromechanics, 5, 56 (2013).]

[30] S.E. Dubowsky, A.N. Rose, N.G. Glumac, B.J. Mc Call. Plasma, 3, 92 (2020). DOI: 10.3390/plasma3030008

[31] V. Stelmashuk, P. Hoffer. IEEE Trans. Plasma Sci., 45, 3160 (2017). DOI: 10.1109/TPS.2017.2770224 
[32] M.L. Shmatov, K.D. Stephan. J. Atmospheric Solar-Terrestrial Phys., 195, 105115 (2019). DOI: $10.1016 /$ j.jastp.2019.105115

[33] R. Friedl, U. Fantz, I. Pilottek, D. Schmid, S. Steibel. Phys. D: Appl. Phys., 54, 095205 (2021). DOI: $10.1088 / 1361-6463 / a b c 918$

[34] В.С. Эдельман. УФН, 130 (4), 675 (1980). [V.S. Edel'man. Sov. Phys. Usp., 23, 227 (1980).]

[35] В.И. Татарский. УФН, $139(4), 587$ (1983). [V.I. Tatarskii. Sov. Phys. Usp., 26, 311 (1983).]

[36] A.I. Nikitin, V.L. Bychkov, T.F. Nikitina, A.M. Velichko, V.I. Abakumov. J. Phys.: Conf. Series, 996, 012011 (2018). DOI: 10.1088/1742-6596/996/1/012011 